NBER WORKING PAPER SERIES

\title{
GROWTH-RATE AND UNCERTAINTY SHOCKS IN CONSUMPTION: CROSS-COUNTRY EVIDENCE
}

\author{
Emi Nakamura \\ Dmitriy Sergeyev \\ Jón Steinsson \\ Working Paper 18128 \\ http://www.nber.org/papers/w18128 \\ NATIONAL BUREAU OF ECONOMIC RESEARCH \\ 1050 Massachusetts Avenue \\ Cambridge, MA 02138 \\ June 2012
}

We would like to thank Mariana Garcia and Channing Verbeck for excellent research assistance. We would like to thank Andrew Ang, Ravi Bansal, Geert Bekaert, Jaroslav Borovicka, John Campbell, John Cochrane, Tim Cogley, Lars Hansen, John Heaton, Ralph Koijen, Lars Lochstoer, Martin Lettau, Sydney Ludvigson, Stavros Panageas, Monika Piazzesi, Bernard Salanie, Martin Schneider, Adrien Verdelhan and seminar participants at various institutions for valuable comments and discussions. We thank the Columbia University Center for International Business Education and Research for financial support. The views expressed herein are those of the authors and do not necessarily reflect the views of the National Bureau of Economic Research.

NBER working papers are circulated for discussion and comment purposes. They have not been peer-reviewed or been subject to the review by the NBER Board of Directors that accompanies official NBER publications.

(C) 2012 by Emi Nakamura, Dmitriy Sergeyev, and Jón Steinsson. All rights reserved. Short sections of text, not to exceed two paragraphs, may be quoted without explicit permission provided that full credit, including $(\odot)$ notice, is given to the source. 
Growth-Rate and Uncertainty Shocks in Consumption: Cross-Country Evidence

Emi Nakamura, Dmitriy Sergeyev, and Jón Steinsson

NBER Working Paper No. 18128

June 2012, Revised May 2016

JEL No. E21,G12

\title{
ABSTRACT
}

We provide new estimates of the importance of growth rate and uncertainty shocks for developed countries. The shocks we estimate are large and correspond to well-known macroeconomic episodes such as the Great Moderation and the productivity slowdown. We compare our results to earlier estimates of "long-run risks" and assess the implications for asset pricing. Our estimates yield greater return predictability and a more volatile price-dividend ratio. In addition, we can explain a substantial fraction of cross-country variation in the equity premium. An advantage of our approach, based on macroeconomic data alone, is that the parameter estimates cannot be viewed as backward engineered to fit asset pricing data. We provide intuition for our results using the recently developed framework of shock-exposure and shock-price elasticities.

\author{
Emi Nakamura \\ Columbia Business School \\ 3022 Broadway, Uris Hall 820 \\ New York, NY 10027 \\ and NBER \\ enakamura@columbia.edu \\ Dmitriy Sergeyev \\ Department of Economics \\ Bocconi University \\ Office 5-e1-02 \\ Via Roentgen, 1 \\ Milan, 20136 \\ Italy \\ dmytro.sergeyev@unibocconi.it
}

\author{
Jón Steinsson \\ Department of Economics \\ Columbia University \\ 1026 International Affairs Building \\ 420 West 118th Street \\ New York, NY 10027 \\ and NBER \\ jsteinsson@columbia.edu
}




\section{Introduction}

The last 120 years have seen huge and very persistent variation in macroeconomic volatility. The period prior to World War I (WWI) was a golden era of low volatility. The outbreak of WWI ushered in a 35 year period of much higher volatility with one crisis following another-WWI, German hyperinflation, Great Depression, World War II (WWII), to name a few. The late 1950s and 1960s were a period of renewed tranquility. But the 1970's and early 1980's again saw a large increase in volatility associated with the rise of OPEC, the breakdown of Bretton Woods, the Iranian Revolution, and the crackdown on inflation initiated by Paul Volcker. Then came the Great Moderation period which lasted until the onset of the Great Recession in 2008. As of this writing, a lively debate rages on whether the next decade will be one of high volatility or a return to the low levels of volatility of the Great Moderation period.

These 120 years have also seen large and persistent swings in average growth rates. Growth was persistently high in the 1920's and persistently low in the early 1930's. It shot up to very high levels for roughly a quarter of a century after the end of WWII before falling substantially and in a sustained way in the 1970's and early 1980's. Growth was high again in the 1990's, but has been persistently low over the past decade, particularly after the onset of the Great Recession.

Many asset pricing models abstract from these phenomena. However, Bansal and Yaron (2004) show that even a modest amount of persistent variation in growth and volatility — which they refer to as "long-run risks" - can play a fundamentally important role in explaining key features of asset prices such as the high equity premium, high volatility of equity returns, and predictability of equity returns. Bansal and Yaron examine U.S. data. But a basic challenge in providing empirical evidence for the long-run risks model is that key parameters of the model are hard to estimate using 80 years of consumption data from a single country.

This challenge has led authors in the asset pricing literature to focus on calibrations of the long-run risks model designed to match asset pricing data (Bansal and Yaron, 2004 (BY); Bansal et al., $2012(\mathrm{BKY}))$ and to estimate the model using a combination of macroeconomic and asset pricing data (Bansal, Kiku, and Yaron, 2007; Constantinides and Ghosh, 2011). A concern with this approach is that the asset pricing data may be driven by other factors such as habits, rare disasters, or heterogeneous agents. ${ }^{1}$ But estimation of long-run risks is typically done in models without these potential alternative explanations. Hence, the estimation algorithm may be "forced"

\footnotetext{
${ }^{1}$ See Campbell and Cochrane (1999), Barro (2006) and Constantinides and Duffie (1996) for influential asset pricing models based on these features.
} 
to generate large estimates of long-run risks to match the asset price data even if these parameters are not justified by the macroeconomic data. In a recent survey, Ludvigson (2013) argues that the quantitative magnitude of long-run risks in macroeconomic data is smaller than standard calibrations assume and unlikely to be large enough to explain the predictability of asset returns. ${ }^{2}$

In this paper, we quantify the importance of growth-rate and volatility shocks using recently assembled data on aggregate consumption for a panel of 16 developed countries over a period of roughly 120 years. By using a dataset that is more than an order of magnitude larger than is typical in the literature, we are able to estimate key parameters much more accurately. An important advantage of our approach is that our estimates are based purely on macroeconomic data. We therefore avoid the concern that our estimates of long-run risks are engineered to fit the asset pricing data, as opposed to being a fundamental feature of the macroeconomic data. We estimate a richer model than BY and BKY. Our model allows for world and idiosyncratic components of growth rate and volatility shocks. It also allows for disasters and for correlation between the growth rate and volatility shocks.

We find strong evidence of long-run risks: we estimate substantial, persistent shocks to growth rates and volatility. Our model captures well-known macroeconomic phenomena such as the Great Depression, the "long and large" fall in volatility over the post-WWII period (Blanchard and Simon, 2001), the Great Moderation, the post-WWII economic miracle in Europe (referred to as the "Wirtschaftswunder" in Germany, the "Trente Glorieuses" in France, and the "Miracolo Italiano" in Italy), the productivity slowdown in the 1970s, as well as the world recessions of 197982, 1990, and 2007-09. Contrary to common belief, our data show clearly that the post-WWII economic miracle in Europe cannot be explained simply as reconstruction after WWII since most of the unusually high growth occurs after the countries in question have surpassed their pre-war, trend-adjusted level of income (see Figure 1).

The growth-rate and volatility shocks we estimate are substantially negatively correlated. The 1960's were both a period of high growth and low volatility, while in the 1970's growth fell and volatility rose. More recently, during the recessions of 1979-1982, 1990 and 2007-2009 growth fell and our estimates of volatility shot up. This negative correlation amplifies the asset pricing implications of long-run risks since it concentrates bad news in certain periods.

We find that it is crucial to distinguish between "world" and country-specific shocks to growth

\footnotetext{
${ }^{2}$ Ludvigson (2013) calibrates a model based on the estimates of Bidder and Smith (2010) who estimate a simplified version of the long-run risks model that abstracts from growth-rate shocks. She notes that estimates of a fully-fledged long-run risks model are needed to fully assess the model.
} 
rates. We estimate a highly persistent process for world growth rates, with a half-life of 13 years. Allowing for a world growth rate component turns out to be crucial in identifying these persistent growth rate shocks, since the country-specific growth rate shocks are far less persistent. One might be concerned that these highly persistent components of growth rates would generate counterfactually high autocorrelations of consumption growth. This is not the case. Our model yields a near-zero autocorrelation of consumption growth at short-to-medium horizons due to the role of transitory shocks to the level of consumption, including disasters.

We analyze the asset pricing implications of our estimated consumption process in a representative agent model with Epstein-Zin-Weil preferences. Our model generates an equity risk premium in line with the data for a coefficient of relative risk aversion (CRRA) of 9. One way to interpret this result is simply as a convenient metric for the amount of risk we estimate. Viewed this way, our estimates yield somewhat more long-run risks than the standard calibrations of BY and BKY.

We highlight three main asset pricing results. First, the countries that are subject to more longrun risks according to our estimates and therefore have higher model-implied equity premia tend to be those countries that have, in fact, seen higher equity premia in the data over our sample period. The correlation of the equity premium in the data and the equity premium in our model across our 16 countries is 0.59 . Hence, we explain a substantial fraction of the cross-country variation in the equity premium using variation in exposure to long-run risk.

Second, our model generates substantially more predictability of excess returns on equity than standard calibrations of the long-run risks model. This lines up well with the data, in which excess returns on equity appear to be substantially predictable at long horizons. ${ }^{3}$ This result addresses Ludvigson's (2013) concern, noted above, that a version of the long-run risks model estimated using macroeconomic data alone would generate even less predictability than the conventional calibrations. The difference arises both from the negative correlation of growth rate and volatility shocks in our model, and the greater volatility of the growth rate shocks in our long-run risk process.

On the other hand, our asset pricing model implies substantially more predictability of consumption growth by price dividend ratios than exists in the data. In a sense, our findings thus deepen the predictability dilemma for the long-run risks model suggested by Beeler and Campbell (2012): The long-run risks model helps explain the return predictability we see in the data, but with a mechanism that implies that consumption growth should be predictable, which we do not

\footnotetext{
${ }^{3}$ The long-term predictability of stock returns has been documented by (Campbell and Shiller, 1988; Fama and French, 1988; Hodrick, 1992; Cochrane, 2008; Binsbergen and Koijen, 2010) among others.
} 
see in the data. ${ }^{4}$

Third, our model generates large and persistent swings in the price-dividend ratio, substantially larger than in standard calibrations of the long-run risks model. This arises because of the high volatility of long-run risk shocks in our model. While BY focused on vanishingly small growth-rate shocks - too small to ever identify in the macroeconomic data-we estimate substantially larger growth-rate shocks. These larger growth-rate shocks, in turn, generate substantially more return volatility. As a consequence, our model is able to fit the volatility of returns endogenously through the high volatility of long-run risks. In contrast, conventional calibrations require the addition of volatile exogenous dividend process to fit the volatility of excess returns.

We provide intuition for our results using the framework of shock-exposure and shock-price elasticities developed by Borovicka, Hansen, and Scheinkman (2014). These elasticities help us understand how sensitive dividends and returns at different horizons are to the different shocks that drive consumption growth in our model. The shock-price elasticities constructed using this methodology underscore the importance of the world long-run risk shocks in our model. The persistent world growth rate shocks are associated with much larger shock-price elasticities than their idiosyncratic counterparts.

The asset pricing exercise we conduct uses a representative agent model that abstracts from disasters, heterogeneity, and habits. However, our estimates in no way rule out the importance of these other phenomena in explaining the behavior of asset prices. Our model matches the equity premium when the CRRA is set to 9 . While this is comparable to the parameters typically used in the long-run risks model, it is high relative to the values typically estimated in the microeconomics literature (Barsky et al., 1997; Chetty, 2006; Paravisini et al. 2010) Thus, our estimates leave ample "room" for additional factors to play a important role in explaining stock prices.

Our paper is related to a large body of work in macroeconomics that studies long-run properties of output growth (Nelson and Plosser, 1982; Campbell and Mankiw, 1989; Cochrane, 1988; Cogley, 1990; Aguiar and Gopinath, 2007) and variation in the volatility of output growth (McConnell and Perez-Quiros, 2000; Stock and Watson, 2002; Bloom, 2009; Ursua, 2010; Bloom et al., 2011; Fernandez-Villaverde et al., 2011; Basu and Bundick, 2011). Our paper builds heavily on the large and growing literature on long-run risks as a framework for asset pricing pioneered by Kandel and Stambaugh (1990) and BY. Important papers in this literature include Bansal and Shaliastovich

\footnotetext{
${ }^{4}$ The confidence intervals on the model's predictions are large, so we cannot formally reject our model given standard significance levels. But a Bayesian would certainly update in the direction of the model being inconsistent with the data regarding consumption predictability.
} 
(2010), Bansal, Dittmar, and Lundblad (2005), Hansen, Heaton, and Li (2008), Bonomo et al. (2011), Malloy, Moskowitz, and Vissing-Jorgensen (2009), Croce, Lettau, and Ludvigson (2010), and Colacito and Croce (2011). See BKY for a more comprehensive review of this literature. We consider a simple representative agent asset pricing framework with known parameter values, taking the consumption process as given. Several theoretical papers extend on this framework, studying the production-based microfoundations for long run risks (e.g., Kaltenbrunner and Lochstoer, 2010; Kung and Schmid, 2011), the asset pricing implications of parameter learning (e.g., Collin-Dufresne, Johannes, and Lochstoer, 2012), deviations from the representative agent framework (e.g., Garleanu and Panageas, 2010), and frameworks where utility depends on more than just consumption (e.g., Uhlig, 2007).

The paper proceeds as follows. Section 2 discusses the data we use. Section 3 presents the empirical model. Section 4 discusses our estimation strategy. Section 5 presents our empirical estimates. Section 6 studies the asset-pricing implications of our model. Section 7 presents intuition for our results on the equity premium based on the shock price and exposure elasticities developed by Borovicka et al. (2011). Section 8 concludes.

\section{Data}

We estimate our model using a long-term dataset on annual per-capita consumer expenditures recently constructed by Robert Barro and Jose Ursua, and described in detail in Barro and Ursua (2008)..$^{5}$ Our sample includes 16 countries: Australia, Belgium, Canada, Denmark, Finland, France, Germany, Italy, Netherlands, Norway, Portugal, Spain, Sweden, Switzerland, United Kingdom, United States. ${ }^{6}$ Our consumption data is an unbalanced panel with data for each country starting between 1890 and 1914 and ending in 2009. Figure 1 plots our data series for France. We have drawn a trend line through the pre-WWII period and extended this line to the present. The figure strongly suggests that France has experienced very persistent swings in growth over the last 120

\footnotetext{
${ }^{5}$ One limitation of the Barro-Ursua data set is that it does not allow us to distinguish between expenditures on non-durables and services versus durables. Unfortunately, separate data on durable and non-durable consumption are not available for most of the countries and time periods we study. For the U.S., non-durables and services are about $70 \%$ as volatile as total consumer expenditures over the time period when both series are available. One way of adjusting our results would therefore be to scale down the volatility of the shocks we estimate by 0.7 . Whether this adjustment is appropriate depends on the extent to which non-durables and services are less volatile at the longer horizons over which our long-run risks shocks are most important. For example, if durables and non-durables are cointegrated, the adjustment is likely to be smaller. The adjustment is also likely to be smaller for earlier points in our sample, when the role of durables in total consumer expenditures was much smaller.

${ }^{6}$ We exclude countries in Southeast Asia and Latin America from our sample. Including these countries raises our estimates of the importance of long-run risks. In this sense, our estimates are conservative.
} 
year. In analyzing the asset pricing implications of our model, we also make use of long-term data on the total nominal returns on stocks and the dividend-price ratio on stocks from Global Financial Data (GFD) as well as data on the total real returns on stocks and bills and inflation rates from Barro and Ursua (2008). Table A.1 gives the sample period we have for each variable for each country.

\section{An Empirical Model of Growth-Rate and Uncertainty Shocks}

We model the "permanent component" of per capita consumption in country $i$ at time $t+1-$ denoted $\tilde{c}_{i, t+1}$-in the following way:

$$
\begin{aligned}
\Delta \tilde{c}_{i, t+1} & =\mu_{i}+x_{i, t}+\xi_{i} x_{W, t}+\eta_{i, t+1}+\xi_{i} \eta_{W, t+1}, \\
x_{i, t+1} & =\rho x_{i, t}+\epsilon_{i, t+1}, \\
x_{W, t+1} & =\rho_{W} x_{W, t}+\epsilon_{W, t+1} .
\end{aligned}
$$

The dynamics of permanent consumption growth are governed by two types of shocks: "randomwalk" shocks that have a one-time effect on permanent consumption growth and "growth-rate" shocks that have a persistent effect on permanent consumption growth. For each type of shock, we allow for a country-specific shock and a shock that is common across all countries (a "world" shock). The four shocks that affect permanent consumption growth are therefore: a country-specific random-walk shock $\left(\eta_{i, t+1}\right)$, a world random-walk shock $\left(\eta_{W, t+1}\right)$, a country-specific growth-rate shock $\left(\epsilon_{i, t+1}\right)$ and a world growth-rate shock $\left(\epsilon_{W, t+1}\right)$. The persistence of the effects of the growthrate shocks on permanent consumption growth is governed by $\operatorname{AR}(1)$ processes $\left(x_{i, t+1}\right.$ and $\left.x_{W, t+1}\right)$. We allow the different countries in our sample to differ in the their sensitivity to the world processes. The differing sensitivity is governed by the parameter $\xi_{i}$.

The volatility of the shocks affecting permanent consumption growth is time-varying and governed by two AR(1) processes - one that is country-specific and another that is common across all countries:

$$
\begin{gathered}
\sigma_{i, t+1}^{2}=\sigma_{i}^{2}+\gamma\left(\sigma_{i, t}^{2}-\sigma_{i}^{2}\right)+\omega_{i, t+1} \\
\sigma_{W, t+1}^{2}=\sigma_{W}^{2}+\gamma\left(\sigma_{W, t}^{2}-\sigma_{W}^{2}\right)+\omega_{W, t+1}
\end{gathered}
$$

We refer to the innovations to these process $-\omega_{i, t+1}$ and $\omega_{W, t+1}$-as uncertainty shocks. ${ }^{7}$

\footnotetext{
${ }^{7}$ Here, we follow Bansal and Yaron (2004)'s original specification for the volatility shocks, which is truncated at a small positive value. We could alternatively model $\log \sigma_{i, t+1}^{2}$ and $\log \sigma_{W, t+1}^{2}$ as following $\mathrm{AR}(1)$ processes. We have experimented with this specification. However, with this specification, the volatility of $\sigma^{2}$ drops to very low
} 
We assume that when world uncertainty rises this affects the volatility of all shocks to permanent consumption. The country specific component of stochastic volatility $\sigma_{i, t+1}^{2}$, however, only affects the country specific shocks. More specifically, for the growth-rate shocks we assume that $\operatorname{var}_{t}\left(\epsilon_{W, t+1}\right)=\sigma_{W, t}^{2}$, while $\operatorname{var}_{t}\left(\epsilon_{i, t+1}\right)=\sigma_{i, t}^{2}+\sigma_{W, t}^{2}$. Variation in $\sigma_{i, t+1}^{2}$ should, therefore, be interpreted as deviations in the uncertainty faced by a particular country from that faced by countries on average. In line with this interpretation, we allow $\sigma_{i, t+1}^{2}$ to be negative as long as $\sigma_{i, t}^{2}+\sigma_{W, t}^{2}$ is positive. For the random-walk shocks, we assume that $\operatorname{var}_{t}\left(\eta_{W, t+1}\right)=\chi_{W}^{2} \sigma_{W, t}^{2}$ and $\operatorname{var}_{t}\left(\eta_{i, t+1}\right)=\chi_{i}^{2}\left(\sigma_{i, t}^{2}+\sigma_{W, t}^{2}\right)$, where $\chi_{i}$ governs the relative volatility of the two country specific shocks, $\epsilon_{i, t+1}$ and $\eta_{i, t+1}$, and $\chi_{W}$ governs the relative volatility of the two common shocks.

We allow for correlation between the growth-rate shocks and the uncertainty shocks. This is meant to capture the possibility that times of high uncertainty may also tend to be times of low growth. Specifically, we allow the country-specific growth-rate shock $\epsilon_{i, t+1}$ and the country-specific uncertainty shock $\omega_{i, t+1}$ to be correlated with a correlation coefficient of $\lambda$. We also allow the world growth-rate shock $\epsilon_{W, t+1}$ and the world uncertainty shocks $\omega_{W, t+1}$ to be correlated with a correlation coefficient of $\lambda_{W}$.

To summarize, we assume the following distributions for the random-walk, growth-rate and uncertainty shocks:

$$
\begin{gathered}
\eta_{i, t+1} \sim \mathrm{N}\left(0, \chi_{i}^{2}\left(\sigma_{i, t}^{2}+\sigma_{W, t}^{2}\right)\right), \\
\eta_{W, t+1} \sim \mathrm{N}\left(0, \chi_{W}^{2} \sigma_{W, t}^{2}\right), \\
{\left[\begin{array}{c}
\epsilon_{i, t+1} \\
\omega_{i, t+1}
\end{array}\right] \sim \mathrm{N}\left(\left[\begin{array}{l}
0 \\
0
\end{array}\right],\left[\begin{array}{cc}
\sigma_{i, t}^{2}+\sigma_{W, t}^{2} & \lambda \sigma_{\omega} \sqrt{\sigma_{i, t}^{2}+\sigma_{W, t}^{2}} \\
\lambda \sigma_{\omega} \sqrt{\sigma_{i, t}^{2}+\sigma_{W, t}^{2}} & \sigma_{\omega}^{2}
\end{array}\right]\right),} \\
{\left[\begin{array}{c}
\epsilon_{W, t+1} \\
\omega_{W, t+1}
\end{array}\right] \sim \mathrm{N}\left(\left[\begin{array}{l}
0 \\
0
\end{array}\right],\left[\begin{array}{cc}
\sigma_{W, t}^{2} & \lambda_{W} \sigma_{W, t} \sigma_{\omega, W} \\
\lambda_{W} \sigma_{W, t} \sigma_{\omega, W} & \sigma_{\omega, W}^{2}
\end{array}\right]\right) .}
\end{gathered}
$$

To avoid negative variances, we truncate the process for $\sigma_{W, t+1}^{2}$ at a small positive value $\zeta$ and we truncate the process for $\sigma_{i, t+1}^{2}$ such that $\sigma_{i, t+1}^{2}>\zeta-\sigma_{W, t^{*}}^{2}{ }^{8}$

levels when $\sigma^{2}$ is small implying that $\sigma^{2}$ can "get stuck" close to zero for a very long time. It is not clear to us that the data support this feature. Also, our MCMC estimation algorithm runs into trouble in this case since the likelihood function is very flat when $\log \sigma^{2}$ becomes sufficiently negative ( $\sigma^{2}$ sufficiently small). In this region very large movements in $\log \sigma^{2}$ correspond to tiny movements in $\sigma^{2}$. This leads the MCMC algorithm to get stuck.

${ }^{8}$ For world stochastic volatility, this means that when an $\omega_{W, t+1}$ is drawn that would yield a value of $\sigma_{W, t+1}^{2}<\zeta$, we set $\sigma_{W, t+1}^{2}=\zeta$. This implies that the innovations to the $\sigma_{W, t+1}^{2}$ have a positive mean when $\sigma_{W, t+1}^{2}$ is close to $\zeta$. For the estimated values of the parameters of our model (baseline estimation), $\sigma_{W, t+1}^{2}=\zeta$ about $9.2 \%$ of the time. We incorporate this truncation in our asset pricing analysis in section 6 . 
We allow parameters to vary across countries whenever our data contains enough information to make this feasible. For example, we allow $\sigma_{i}^{2}$ to differ across countries. This allows some countries to have permanently higher or lower volatility of macroeconomic shocks than others. However, some parameters are difficult to estimate precisely for each country individually. In these cases, we rely on the panel structure of the data set and assume that these parameters are common across countries. The parameters we make this pooling assumption for are: the persistence of the growthrate components $\rho$ and $\rho_{W}$, the persistence of the stochastic volatility processes $\gamma$, the volatility of the uncertainty shocks $\sigma_{\omega}^{2}$ and $\sigma_{W, \omega}^{2}$, the average volatility of the world stochastic volatility process $\sigma_{W}^{2}$, the relative standard deviation of the world random-walk and growth-rate shocks $\chi_{W}$, and the correlations between the growth-rate and uncertainty shocks $\lambda$ and $\lambda_{W} \cdot{ }^{9}$

We allow measured consumption- denoted $c_{i, t}$ - to differ from permanent consumption $\tilde{c}_{i, t}$ because of two transitory shocks:

$$
c_{i, t+1}=\tilde{c}_{i, t+1}+\nu_{i, t+1}+I_{i, t+1}^{d} \psi_{i, t+1}^{d}
$$

The first of these shocks $\nu_{i, t+1}$ is mainly meant to capture measurement error. We assume that this shock is distributed $\mathrm{N}\left(0, \sigma_{i, t, \nu}^{2}\right)$, where the volatility of this shock is allowed to differ before and after 1945. By incorporating this break in the volatility of $\nu_{i, t+1}$ we can capture potential changes in national accounts measurement around this time (Romer, 1986; Balke and Gordon, 1989). This is empirically important since it avoids the possibility that our estimates of the high persistence of macroeconomic uncertainty arise spuriously from these changes in measurement procedures. ${ }^{10}$

The second shock $I_{i, t+1}^{d} \psi_{i, t+1}^{d}$ captures transitory variation in consumption due to disasters. ${ }^{11}$ The dummy variable $I_{i, t}^{d}$ is set equal to one in periods identified as disaster periods by Nakamura et al. (2010) - almost exclusively WWI, the Great Depression, and WWII - and during a two-year recovery period after each such episode and zero otherwise. ${ }^{12}$ The disaster shock $\psi_{i, t}^{d}$ is distributed $\mathrm{N}\left(\mu_{d}, 1\right)$. We fix the variance of $\psi_{i, t}^{d}$ at 1 (a large value), to ensure that this shock "soaks up" all transitory variation in consumption during the disaster periods. Allowing for this separate disaster shock avoids the concern that we are overestimating long-run risks in the persistent component of

\footnotetext{
${ }^{9}$ Notice also, that we assume that the same parameter $(\gamma)$ governs the persistence of both the common and countryspecific components of stochastic volatility. We do this because there is insufficient information in our dataset to estimate a separate parameter for the persistence of world volatility.

${ }^{10}$ We restrict $\nu_{i, t+1}$ to be i.i.d. to avoid the identification problem discussed in Quah (1992).

${ }^{11}$ The permanent effects of disasters are captured by $\eta_{i, t+1}, \eta_{W, t+1}, \epsilon_{i, t+1}$, and $\epsilon_{W, t+1}$.

${ }^{12}$ Nakamura et al. (2010)'s results indicate that there is unusually high growth after disasters - i.e., recoveries - but that this unusually high growth dies out rapidly - it has a half-life of 1 year. By allowing for a two year recovery period after disasters, we allow the disaster shocks in our model to capture the bulk of the unusually high growth after disasters and avoid having this growth variation inflate our estimates of long-run risks.
} 
consumption due to the huge but transitory spike in volatility during WWI, the Great Depression, and WWII.

To summarize, our model extends the long-run risks model of Bansal and Yaron (2004) in four ways. First, we allow for both a country-specific and world component of all the main shocks in the model and we allow each country to differ in their sensitivity to the world shocks. Second, we allow the growth-rate and uncertainty shocks to be correlated. This allows for the possibility that times of low growth may also tend be times of high uncertainty. Third, we allow for time-variation in measurement error in consumption. This is crucial since it avoids the outcome that our estimates of the high persistence of macroeconomic uncertainty arise spuriously from changes in measurement procedures. Fourth, we allow for disasters - again key for avoiding the overestimation of stochastic volatility. Finally, we estimate the model using panel data on many countries and use the panel structure of the data to identify certain key parameters.

\section{Estimation}

The model presented in section 3 contains a large number of unobserved state variables, since it decomposes consumption into several unobserved components. We estimate the model using Bayesian MCMC methods. ${ }^{13}$ To carry out our Bayesian estimation we need to specify a set of priors on the parameters of the model. We choose highly dispersed priors to minimize their effect on our inference:

$$
\begin{array}{rlrl}
\rho & \sim \mathrm{U}(0.005,0.995), & \rho_{W} & \sim \mathrm{U}(0.005,0.995), \\
\sigma_{\omega}^{2} & \sim \mathrm{U}\left(10^{-12}, 2.5 \times 10^{-9}\right), \sigma_{W, \omega}^{2} & \sim \mathrm{U}\left(10^{-12}, 4 \times 10^{-10}\right), \\
\lambda & \sim \mathrm{U}(-0.995,0.995), & \lambda_{W} & \sim \mathrm{U}(-0.995,0.995), \\
\chi_{W}^{2} & \sim \mathrm{U}\left(10^{-4}, 25\right), & \chi_{i}^{2} & \sim \mathrm{U}\left(10^{-4}, 25\right), \\
\gamma & \sim \mathrm{U}(0.005,0.98), & \sigma_{\nu, i}^{2} & \sim \mathrm{U}\left(10^{-8}, 10^{-2}\right), \\
\xi_{i} & \sim \mathrm{U}\left(10^{-4}, 1\right), & \sigma_{i}^{2} & \sim \mathrm{U}\left(10^{-8}, 0.0004\right), \\
\mu_{i} & \sim \mathrm{N}(0.015,0.030), & \mu_{d} & \sim \mathrm{N}(0,1),
\end{array}
$$

We normalize the unconditional volatility of the world stochastic volatility process to be $\sigma_{W}=$ 0.005. Since we allow the loadings on the world volatility process to vary across countries, $\sigma_{W}$ is

\footnotetext{
${ }^{13}$ Our algorithm samples from the posterior distributions of the parameters and unobserved states using a Gibbs sampler augmented with Metropolis steps when needed. This algorithm is described in greater detail in appendix A. The estimates discussed in section 5 for the three versions of the model, are each based on four independent Markov chains. Each of these chains has 5 million draws or more with the first 1 million draws from each chain dropped as "burn-in". To assess convergence, we employ Gelman and Rubin's (1992) approach to monitoring convergence based on parallel chains with "over-dispersed starting points" (see also Gelman, 2004, ch. 11).
} 
unidentified unless volatility hits its lower bound. ${ }^{14}$ We assume that the initial values of $x_{i, t}, x_{W, t}$, $\sigma_{i, t}$ and $\sigma_{W, t}$ are drawn from their unconditional distributions. We assume that the initial value of $\tilde{c}_{i t}$ for each country is drawn from a highly dispersed normal distribution centered on the initial observation for $c_{i, t}$.

\section{$5 \quad$ Empirical Results}

Our baseline empirical results are for the full model described in section 3 for the full sample period 1890-2009. We also report results for a shorter post-WWII sample period and for a simplified version of the model in which we shut down the world growth-rate and volatility components as well as the correlation between the country-specific growth-rate and volatility shocks. We refer to this latter model as the "simple model." Tables 1-3 present parameter estimates for these three cases. For each parameter, we present the prior and posterior mean and standard deviation. We refer to the posterior mean of each parameter as our point estimate for that parameter.

Overall, we find evidence for large amounts of long-run risk. A large fraction of consumption volatility arises from persistent growth-rate shocks (roughly 40\%) and these shocks are quite persistent. These shocks lead to extended periods of high and low growth, despite the moderate short-term autocorrelation of consumption growth. We also identify large and persistent variation in volatility over time. Volatility is roughly 5 times higher at the 95 th quantile of its distribution than it is at the 5th quantile. Finally, our model implies that the component of the growth-rate process that is common across countries is much more persistent than the component of these shocks that is idiosyncratic to particular countries. This explains why consumption growth is more correlated across countries at low than high frequencies. These facts have important implications for asset pricing, as we describe in section 6.

\subsection{Examining the Shocks}

Perhaps the best way to illustrate the importance of long-run risks in our estimates is to simply plot our estimates of the growth-rate and volatility processes. Figure 2 plots our estimate of the world growth-rate process. The most striking feature of our estimates for this process is its high

\footnotetext{
${ }^{14}$ In the absence of the lower bound on volatility, this parameter would not be identified. Given the presence of the lower bound, the parameter is (weakly) identified by the effect of the truncation on the mean of the process. Given that there is no economic logic for the identification of this parameter, we choose to fix it.
} 
values in the 1950 's, 60 's and early 70's. This reflects the post-WWII European growth miracle. ${ }^{15}$ Our estimated world growth-rate process also captures several major recessions such as the 197982 recession following the spike in oil prices that accompanied the Iranian Revolution as well as the tightening of U.S. monetary policy, the recession of 1990 following, among other events, the Persian Gulf War, the unification of Germany, and the accompanying tightening of German monetary policy, and the Great Recession of 2007-2009. Earlier in our sample, our world growthrate process captures the relatively high growth in the 1920s and the dismal growth of the Great Depression and WWII. ${ }^{16}$

Figure 3 presents our estimates of the evolution of the world stochastic volatility process $\left(\sigma_{W, t}\right)$. We estimate a large increase in world volatility during the Great Depression and WWII. World volatility remained high in the late 1940's and 1950's. It then fell to very low levels in the 1960's, but was high again in the 1970's and early 1980's. World volatility fell sharply in the mid-to-late 1980's but was relatively high in the early 1990's. From 1995 to 2007 the world experienced a long period of relative tranquility. At the end of our sample period, world volatility rose sharply once again. In studying this figure, it is important to keep in mind that our model attributes much of the volatility in the first half of our sample to disasters and measurement error.

Comparing Figures 2 and 3, it is evident that the world growth-rate process and the world stochastic volatility process are negatively correlated. Our model allows explicitly for a correlation between shocks to these processes $\left(\lambda_{W}\right)$. Table 1 reports that our estimate of this correlation is -0.42. We also estimate a common correlation between the country-specific growth-rate and uncertainty shocks in our data and find this correlation to also be -0.47 . Our estimates, thus, strongly suggest that periods of high volatility are also periods of low growth.

We estimate a substantial amount of heterogeneity in the evolution of volatility across countries. Figure 4 presents our estimates of the evolution of the volatility process for the U.S., the U.K. and Canada- $\left(\sigma_{i, t}^{2}+\sigma_{W, t}^{2}\right)^{1 / 2}$ in our notation. ${ }^{17}$ For the United States our results reflect the "long and large" decline in macroeconomic volatility documented by Blanchard and Simon (2001) and

\footnotetext{
${ }^{15}$ It is intriguing that this growth spurt so closely followed World War II. It is tempting to infer that this high growth is due to post-war reconstruction. However, for most countries, the vast majority of the unusually high growth during this period occurred in years when consumption (and output) had surpassed its pre-WWII trend-adjusted level (see, e.g., Figure 1).

${ }^{16}$ Recall, though, that the temporary effects of WWII on the level of consumption are "soaked up" by the disaster shock we allow for. Only the permanent effects of WWII are captured in our estimates of the world growth-rate process.

${ }^{17}$ Recall that $\sigma_{i, t}^{2}$ can be negative (as long as $\sigma_{i, t}^{2}+\sigma_{W, t}^{2}$ is positive) and should be interpreted as the difference between country-specific volatility and world volatility.
} 
well as the rather abrupt decline in volatility in the mid-1980's documented by McConnell and Perez-Quiros (2000) and Stock and Watson (2002). The experience of the U.K. is quite different. Volatility in the U.K. was lower in the early part of the 20th century (excluding disasters), but then rose substantially over the first three decades after WWII. Volatility in the U.K. began falling only around the time Margaret Thatcher came to power and has remained elevated relative to volatility in the U.S. ever since 1960. In contrast, volatility in Canada fell much more abruptly in the 1950's and early 1960's than volatility in the U.S. and was substantially below U.S. volatility in the 1960's, 1970's and early 80's at which point U.S. volatility converged down to similarly low levels.

We estimate a substantial decline in the volatility of transitory shocks $\sigma_{\nu, i}$ after 1945 in most countries. Before 1945, the standard deviation of these transitory shocks is quite large $-2.3 \%$ for the median country. After 1945, it is only $0.4 \%$ for the median country. This change likely reflects in part changes in national accounts measurement, as we discuss in section $3 .^{18}$

\subsection{Comparison with BY and BKY}

In both the original calibration of the long-run risks model in BY and the more recent calibration of BKY, long-run risks are relatively small; so small that they are hard to detect in macroeconomic data. In contrast, the long-run risks we estimate are relatively large. Table 2 reports that roughly $40 \%$ of the volatility of consumption growth derives from the long-run risk shocks in our estimated model, while in the calibrations of BY and BKY, this ratio is only 20-25\%. The long-run risks we estimate are therefore roughly twice the size of those considered by BY and BKY.

The amount of stochastic volatility we estimate is also much larger than that considered by BY, but comparable to the amount of stochastic volatility in BKY. To illustrate this, Table 2 reports the counter-factual volatility of consumption growth in the United States if the stochastic volatility processes were permanently "stuck" at the 5th, 50th, and 95th quantiles of their distributions. ${ }^{19}$ We find that the volatility of consumption growth is more than 5 times higher at the 95th quantile than it is at the 5 th quantile (0.038 versus 0.007$)$. In the calibration of BY, this ratio is only 1.48 (0.034 versus 0.023$)$, while it is 5 in the calibration of BKY (0.045 versus 0.009).

\footnotetext{
${ }^{18}$ Ursua (2010) argues - based on methods developed by Romer (1986) - that this change also reflects changes in macroeconomic fundamentals. Since transitory shocks turn out to be relatively unimportant for asset pricing, the choice of whether to treat this change as a consequence of measurement or fundamental shocks plays a small role in our asset pricing analysis.

${ }^{19}$ The comparison with BY and BKY is complicated since their model is formulated at a monthly frequency, while we estimate our model at an annual frequency. This complication is what leads us to use the statistics described here rather than compare the parameter estimates directly.
} 
Table 2 also reports the persistence of the growth-rate and uncertainty processes we estimate in terms of half-lives. The half-lives of the world and country-specific growth-rate processes that we estimate are 8.5 years and 1.2 years, respectively. These estimates straddle the persistence of the growth-rate processes considered in BY and BKY (half-lives of 2.7 years and 2.3 years, respectively). Interestingly, the results we report for our "simple model" show that it is crucial to allow for a world component in order to be able to capture the highly persistent movements in growth rates in the data. In the simple model, the half-life of the growth-rate shocks is only 1.9 years and an analysis of the residuals from this model confirms that it is not able to capture well the low frequency movements in growth-rates. The persistence of the uncertainty process we estimate (half-life of 22 years) is much higher than the persistence of the uncertainty process in BY's original calibration. But it is not as high as the very high persistence considered in BKY (half-life of 57.7 years).

\subsection{Autocorrelations, Cross-Country Correlations, and Variance Ratios}

A challenge in matching the empirical properties of aggregate consumption data is that, on the one hand, variance ratios - which provide evidence on the long-run autocorrelation of consumptionsuggest substantial persistence in consumption growth rate. However, on the other hand, if one simply looks at autocorrelations at short and medium horizons, the autocorrelations are close to zero, suggesting low persistence.

Table 4 illustrates these effects. The first panel reports estimates of autocorrelations in the estimated model (excluding disasters). ${ }^{20}$ In the data, the autocorrelation of consumption growth is positive but small at short to medium-term horizons for the median country. For the US, the autocorrelation oscillates around zero at different horizons. At the same time, Table 4 shows that, in the data, the variance ratio for consumption growth for the median country is 1.53 , substantially above one. For the U.S. the corresponding figure is 1.29. Variance ratios above one indicate reduced form evidence for positive autocorrelation of consumption growth. ${ }^{21}$

\footnotetext{
${ }^{20}$ In the data, we exclude disasters by subtracting from the raw data our estimate of the transitory disaster shock. This yields series for consumption that smoothly "interpolate" through disasters. For the simulated data from our model, we simulate the model without the transitory disaster shock.

${ }^{21}$ The definition and intuition behind variance ratios is discussed in more detail in appendix B. The high value of the variance ratio for the U.S. contrasts with the well known results of (Cochrane, 1988), who estimates a much smaller variance ratio for U.S. output. Several factors contribute to the difference. First, the variance ratio for consumption is somewhat higher than for output. Second, we are looking at a somewhat longer sample period than Cochrane and the variance ratios are somewhat higher for this longer sample period. Third (and most important), the variance ratio excluding disasters is substantially larger than that including disasters since disasters are typically followed by recoveries and therefore lower the variance ratio (Kilian and Ohanian, 2002; Nakamura et al., 2012).
} 
Our model is able to fit both types of evidence on the persistence of consumption growth. On the one hand, the model generates modest short and medium-term autocorrelations in the growth rate of consumption. This is because the positive autocorrelation arising from the growth-rate process is mostly off-set by the negative auto-correlation generated by the transitory shocks to the level of consumption. On the other hand, the long-run risks shocks to growth generate variance ratios substantially above one: 1.33 for the median country and 1.39 for the U.S.

We also compute an analogous variance ratio measure for assessing the persistence of shocks to volatility, introduced by Bansal and Yaron (2004). This statistic provides a rough measure of the persistence of stochastic volatility. As with the variance ratio for consumption growth, if this variance ratio is above one, it indicates that uncertainty shocks have persistent effects on volatility - i.e., high volatility periods are "bunched together" (the exact definition is presented in appendix B). In the data, the variance ratios for realized volatility are again substantially above one (2.10 for the median country and 1.80 for the U.S.). This is hardly surprising given the long swings in volatility associated with phenomena such as the Great Moderation that the model is intended to fit. Again, the model fits this feature of the data quite well. It yields a value of 1.93 for the median country and 2.12 for the U.S.

The last panel of Table 4 presents cross-correlations across consumption growth in different countries, at different horizons. The correlation of consumption growth across countries is estimated to be substantial and to grow with the horizon, a point emphasized by Cogley (1990). The median one-year cross-country correlation in the data is 0.21 , while it is 0.43 at the five-year horizon and 0.55 at the ten-year horizon. Our model provides an excellent fit to the data along this dimension. In the model, the one-year cross-country correlation is 0.15 , while it is 0.36 and 0.45 at five- and ten-year horizons, respectively, for the median country. These long-run correlations help explain observed cross-country comovement in asset returns (e.g., Colacito and Croce, 2011; Verdelhan, 2012).

\section{Asset Pricing}

We analyze the asset pricing implications of the model of aggregate consumption described in section 3 within the context of a representative consumer endowment economy with Epstein-Zin-

Ursua (2010) presents a related analysis. Rather than filtering the data the way we do, he excludes "outlier" growth observations. This simpler procedure also yields substantially larger variance ratios than raw consumption growth in his broader sample. 
Weil preferences (Epstein and Zin, 1989; Weil, 1990). For this preference specification, Epstein and Zin (1989) show that the return on an arbitrary cash flow is given by the solution to the following equation:

$$
E_{t}\left[\beta^{\theta}\left(\frac{C_{i, t+1}}{C_{i, t}}\right)^{(-\theta / \psi)} R_{c, t, t+1}^{-(1-\theta)} R_{i, t, t+1}\right]=1,
$$

where $R_{i, t, t+1}$ denotes the gross return on an arbitrary asset in country $i$ from period $t$ to period $t+1$, $R_{c, t, t+1}$ denotes the gross return on the agent's wealth, which in our model equals the endowment stream. The parameter $\beta$ represents the subjective discount factor of the representative consumer. The parameter $\theta=\frac{1-\gamma}{1-1 / \psi}$, where $\gamma$ is the coefficient of relative risk aversion (CRRA) and $\psi$ is the intertemporal elasticity of substitution (IES), which governs the agent's desire to smooth consumption over time.

We begin by calculating asset prices for two assets: a risk-free one-period bond and a risky asset we will use to represent equity. The risk-free one-period bond has a certain pay-off of one unit of consumption in the next period. We follow BKY in modeling equity as having a levered exposure to the stochastic component of permanent consumption. Specifically, the growth rate of dividends for our equity claim is

$$
\Delta d_{t+1}=\mu+\phi\left(x_{i, t}+\xi_{i} x_{W, t}+\eta_{i, t+1}\right)
$$

where $\phi$ is the leverage ratio on expected consumption growth (Abel, 1999). We base our analysis on the posterior mean estimates for the baseline case from section 5 . We therefore abstract from learning, doubt, and fragile beliefs (Timmermann, 1993; Pastor and Veronesi, 2009; Hansen, 2007; Hansen and Sargent, 2010; Croce, Lettau, and Ludvigson, 2010). We do not, however, mean to downplay the importance of these factors. Indeed, the importance of long-run risks are likely to raise the extent of parameter uncertainty, given how hard it is to estimate the long-run risk parameters. Weitzman (2007) shows that parameter uncertainty can massively increase the equity premium.

The asset-pricing implications of our model with Epstein-Zin-Weil (EZW) preferences cannot be derived analytically. We solve for asset prices in our model using standard grid-based numerical methods of the type used, e.g., by Campbell and Cochrane (1999) and Wachter (2005). ${ }^{22}$ We choose

\footnotetext{
${ }^{22}$ We solve the integral in equation (9) on a grid. Specifically, we start by solving for the price-dividend ratio for a consumption claim. In this case we can rewrite equation (9) as $P D R_{t}^{C}=E_{t}\left[f\left(\Delta C_{t+1}, P D R_{t+1}^{C}\right)\right]$, where $P D R_{t}^{C}$ denotes the price dividend ratio of the consumption claim. We specify a grid for $P D R_{t}^{C}$ over the state space. We then solve numerically for a fixed point for $P D R_{t}^{C}$ as a function of the state of the economy on the grid. We can then rewrite equation (9) for other assets as $P D R_{t}=E_{t}\left[f\left(\Delta C_{t+1}, \Delta D_{t+1}, P D R_{t+1}^{C}, P D R_{t+1}\right)\right]$, where $P D R_{t}$ denotes the price dividend ratio of the asset in question and $\Delta D_{t+1}$ denotes the growth rate of its dividend. Given that we have already solved for $P D R_{t}^{C}$, we can solve numerically for a fixed point for $P D R_{t}$ for any other asset as a function of
} 
a subjective discount factor of $\beta=0.99$ to fit the observed average risk-free rate in our baseline specification. We follow BY in choosing an IES of $\psi=1.5$, and a leverage parameter of $\phi=3$. We choose a CRRA of $\gamma=9$ to match the equity premium in U.S. data.

Qualitatively, leverage and risk aversion play the same role in raising the risk premium but they enter somewhat differently in the return formulas. In our setting with stochastic volatility, leverage has a non-linear effect on the equity premium because it not only makes the shocks hitting dividends proportionally larger, but also it makes shocks to stochastic volatility effectively larger. ${ }^{23}$

To evaluate the asset pricing implications of long-run risks, we calculate asset prices as though all risk was associated with risk in "permanent consumption." This measure excludes the transitory (measurement error) shock and the transitory variation in consumption during disasters - primarily WWI, WWII and the Great Depression.

The asset pricing implications of disaster risk have been the focus of a large recent literature (see, e.g., Barro, 2006). Indeed, two of the authors of the present paper (Nakamura and Steinsson) have quantified the asset pricing implications of disaster risk using similar methods to those employed in this paper (Nakamura, et al., 2010). However, what we seek to show here is that one does not have to believe in the importance of disaster risk to believe long-run risks have important asset pricing implications. Even if one believes that events such as WWI, WWII and the Great Depression will not occur in the future, one still has to contend with the existence of smaller but much more persistent changes in growth rates and volatility - the focus of our paper. Hence, we believe that the asset pricing implications of long-run risks are worthy of analysis in isolation. ${ }^{24}$ Note that if we do not account separately for disaster risk and instead allow these events to influence our estimates of long-run risks, then our estimates of the importance of long-run risks, and particularly stochastic volatility become even larger - in this sense, our baseline estimates are conservative. Also, for the post-WWII sample the handling of disaster risk is a unimportant since essentially no disasters have occurred after WWII according to our definition in the sample of countries we analyze. ${ }^{25}$

\footnotetext{
the state of the economy on the grid.

${ }^{23}$ BY model leverage by considering a scaled up dividend claim, in line with Abel (1999), who shows that this formulation works well in replicating the asset pricing implications of true leverage in a number of settings but does not analyze a model with stochastic volatility. This would be a useful topic for future research.

${ }^{24}$ In addition, while it would certainly be interesting to explore the implications of interactions between disasters and long-run risks, this would entail considerable costs in terms of computational complexity.

${ }^{25}$ When we analyze the predictability of returns and consumption growth in section 6.2 we simulate consumption growth adding back in our estimated process for "measurement error."
} 


\subsection{The Equity Premium}

Table 5 presents key asset pricing statistics in the data and for our baseline specification of the model. The table presents results for the U.S. and for the median country in our sample. Our model matches the observed equity premium for the United States with a CRRA of 9, a slightly lower value than is used in BY and BKY. This value is roughly an order of magnitude lower than the value needed in a model without long-run risks (Mehra and Prescott, 1985; Tallarini, 2000). Long-run risks make the world a riskier place, and households must be compensated to hold equity which is exposed to these risks. Recall that our estimates of long-run risks are based solely on macroeconomic data. The amount of long-run risk we estimate is therefore not backward engineered to match the equity premium for a modest value of the CRRA. In light of this, our finding that the quantity of long-run risks is somewhat larger than in BY and BKY is of particular interest. ${ }^{26}$

Table 6 presents results on the equity premium and the risk free rate from our baseline model for all 16 countries in our sample. Interestingly, the model-generated equity premium varies substantially across countries - ranging from $4.7 \%$ to $12.5 \%$ with an average of $7.7 \%$. This variation arises because we allow for a rich array of heterogeneity across countries (e.g., different sensitivity to the world growth-rate component, different average volatility of the country-level growth-rate component, different average volatility of the random-walk shocks, etc.).

Figure 5 plots the equity premium in the model versus the equity premium in the data across the 16 countries in our sample. Despite the small number of countries, and many simplifying assumption in our model, there is a clear positive correlation of 0.59 between the model-generated equity premium and the equity premium observed in the data. Countries with higher loadings on the world long-run risks factors as well as larger random-walk shocks have higher equity premia in the data.

Table 6 also presents results on the equity premium for a case where we "turn off" the uncertainty shocks in the model. This "constant volatility" model yields equity premia that are roughly half as large as the full model, implying that roughly half of the equity premium in our model results from the growth-rate shocks and the other half from the uncertainty shocks. Finally, Table 6 present results on the equity premium for a third case where we eliminate all long-run risks and

\footnotetext{
${ }^{26}$ Table A.3 in the appendix presents analogous results to Table 5 for our two alternative specifications: the simple model and the post-WWII estimation of the baseline model. Results for both cases are quite similar to the baseline case.
} 
re-calibrate the volatility of the random-walk shocks to match the volatility of $\Delta \tilde{c}_{i, t}$. This case corresponds closely to the model considered by Mehra and Prescott (1985). It generates equity premia of only around $1 \%$.

As we discuss above, we allow for a correlation between the growth-rate and uncertainty shocks in our model. This correlation is estimated to be substantially negative (Table 1). The negative correlation contributes to raising the equity premium in our model. Since negative growth-rate shocks and shocks that increase uncertainty both raise marginal utility, being hit by both at the same time is particularly painful for the representative agent. We have re-calculated asset prices for a case with $\lambda=\lambda_{W}=0$ but keeping other parameters unchanged. This yields an equity premium that is about 1.4 percentage points smaller for the U.S. than our baseline case.

\subsection{Return Predictability}

Our model generates substantial predictability in equity returns as a function of the price dividend ratio. This lines up well with a large literature in finance documenting long-horizon return predictability of equity returns in the data (Campbell and Shiller, 1988; Fama and French, 1988; Hodrick, 1992; Cochrane, 2008; Binsbergen and Koijen, 2010). ${ }^{27}$ The source of the return predictability in the long-run risks model is uncertainty shocks. A positive uncertainty shock leads to a stock market decline with no corresponding effect on expected dividends-implying that expected returns will be high going forward.

To evaluate the fit of the model to the data along this dimension, we estimate equations of the following form

$$
y_{i, t+5}=\alpha_{i}+\beta_{i} p d_{i, t}+\epsilon_{i, t+5}
$$

where $p d_{i, t}$ denotes the logarithm of the price-dividend ratio on equity and $y_{i, t+5}$ is one of three things: the five-year excess return on stocks, the five-year realized volatility of consumption growth, or the five-year growth rate of consumption. ${ }^{28}$ We run these regressions in the data and on simulated datasets of the same length (120 years) from our model. We report the median from 1000 such simulations, as well as the $2.5 \%$ and $97.5 \%$ quantiles.

\footnotetext{
${ }^{27}$ The statistical significance of return predictability has been hotly debated (see, e.g., Stambaugh, 1999; Ang and Bekaert, 2007). Recent work by Lewellen (2004) and Cochrane (2008) has exploited the stationarity of price-dividend ratios and the lack of predictability of dividend growth to develop more powerful tests of return predictability. These tests reject the null of no predictability of returns at the $1-2 \%$ level.

${ }^{28}$ We use the absolute value of the residual from an $\mathrm{AR}(1)$ regression for consumption growth, summed over 5-year intervals, as our measure of realized volatility, following Bansal et al. (2005).
} 
The first panel of Table 7 presents results on the predictability of excess returns. Our point estimates imply a large degree of predictability of returns in the U.S. data. The regression coefficient on the price-dividend ratio is -0.41 and the R-squared of the regression is 0.24 . However, the U.S. is a bit of an outlier in terms of the strength of this predictability. For the median country, the regression coefficient is -0.30 and the R-squared is 0.11 in the data. Our baseline model generates a median regression coefficient for the U.S. of -0.38 and R-squared of 0.10 and similar results for the median country. The values for the data lie comfortably within the $95 \%$ probability intervals generated by the model.

In a recent survey, Ludvigson (2013) conjectures that a reasonably calibrated long-run risks model cannot fit the evidence of return predictability in the data. She notes that conventional calibrations of the long-run risks model explain a substantially lower fraction of variation in expected returns (R-squared less than 0.05) and that an estimated version of the model generates even less. Her analysis is based on estimates of a simplified version of the long-run risks model by Bidder and Smith (2010) in which the R-squared of the return predictability regression for the estimated version of the long-run risks model is essentially zero. Our model shows that, in fact, a fully estimated version of the long-run risks model generates more rather than less return predictability than in the calibrations of BY and BKY.

On the other hand, our model implies too much predictability of consumption growth. Given the degree of predictability we find in growth rates, our asset pricing model suggests the price dividend ratio should predict future consumption growth: the median R-squared implied by the model is 0.26 , and the coefficient on the price-dividend ratio is 0.19 . The confidence intervals on the model's predictions are large, so we cannot formally reject our model. But the R-squared and coefficient on the price-dividend ratio from the data are clearly at the bottom of the confidence interval from the model (0.03 and 0.04 respectively in the median country).

The key feature of our model in generating return predictability is stochastic volatility. Two features of our stochastic volatility process contribute to greater return predictability than in BY and BKY. First, the correlation between growth rate and uncertainty shocks implies that even when a high price-dividend ratio arises from a positive growth rate shock, it portends higher expected returns, since uncertainty is also likely to be low. Second, the large amount of stochastic volatility in our model arises through a somewhat different mechanism than BKY. While the persistence of our uncertainty shocks process is lower, the uncertainty shocks themselves pertain to a much more volatile long-run risk process. This generates more variation in uncertainty at a medium-term 
horizon, and more predictability of returns.

The price-dividend ratio on stocks also has substantial predictive power for realized volatility of consumption growth in both the data and model. For U.S. data, the regression coefficient is -0.81 and the R-squared is $0.32 .{ }^{29}$ For the median country, the regression coefficient is -0.38 and the R-squared is 0.19. Our model helps explain this pattern in the data. Our baseline model generates a median regression coefficient of -0.52 and an R-squared of 0.09 for the U.S. and similar results for the median country. Again, the values in the data are well within the $95 \%$ probability intervals generated by the model.

A related way to test this prediction is to study the comovement of the time series of realized volatility and the price-dividend ratio. The relationship above suggests that the two should move in opposite directions, or equivalently that realized volatility should comove with the dividendprice ratio (inverse of the price-dividend ratio). Figure 6 plots our estimate of the evolution of realized volatility in the U.S. along with the dividend-price ratio on stocks. There is a substantial comovement between economic uncertainty and the value of the stock market, as emphasized by Lettau et al. (2008). Figure A.1 in the web appendix presents analogous plots for all countries in our sample, extending the results of Lettau et al. (2004), and illustrating that the comovement appears to hold in many countries after 1970.

A recent critique of the long-run risks model by Beeler and Campbell (2012) is that it generates too much predictability of consumption growth. The third panel of Table 7 presents statistics on the performance of the model along this dimension. The empirical results on consumption predictability do lie within the confidence interval generated by our model. However, the empirical value is clearly at the lower end of the interval, in line with Beeler and Campbell's results.

\subsection{Volatility of the Price-Dividend Ratio}

An additional interesting feature of our empirical results is that the estimated model generates large and persistent swings in the price-dividend ratio. The volatility of the price-dividend ratio is 0.26 , about a third higher than in BK and BKY. This difference arises because of the high volatility of long-run risk shocks in our model. While BY focused on vanishingly small growth-rate shocks - too small to ever identify in the macroeconomic data - we estimate substantially larger growth-rate shocks.

This same feature of the empirical estimates also endogenously generates a high volatility of

\footnotetext{
${ }^{29}$ These results extend and reinforce earlier results by Bansal et al. (2005).
} 
equity returns. Our model generates a standard deviation of equity returns for the US of $13 \%$. A key point to emphasize about this result is that the high volatility of returns arises even without adding an extra shock to the dividend process, as in conventional calibrations of the long-run risks model.

\subsection{Bonds and Exchanges Rates}

The model also yields interesting implications regarding the term structure of bonds and regarding the volatility of exchange rates. To analyze the term structure, we approximate long-term bonds by a perpetuity with coupon payments that decline over time by $10 \%$ per year. This yields a bond with a duration similar to that of 10-year coupon bonds. In our model, the term-premium for this real long-term bond is $-2.4 \%$. Piazzesi and Schneider (2006) document that the real yield curve in the United Kingdom has been downward sloping, while it has been mostly upward sloping in the United States. They caution, however, that this evidence is hard to assess because of the short sample and poor liquidity in the U.S. TIPS market. ${ }^{30}$

In a world with complete markets, the log change in the real exchange rate between two countries is

$$
\Delta e_{t}=m_{t}^{*}-m_{t}
$$

where $e_{t}$ denotes the log real exchange rate (home goods price of foreign goods), and $m_{t}$ and $m_{t}^{f}$ are the logarithm of the home and foreign stochastic discount factors, respectively. Hansen and Jagannathan (1991) show that $\sigma\left(M_{t}\right) R_{t}^{f} \geq E\left(R_{t}^{e}\right) / \sigma\left(R_{t}^{e}\right)$, where $M_{t}$ is the level of the stochastic discount factor and $R^{e}$ is the excess return on the stock market. From Table 5 we can see that $R^{f} \simeq 1.01, E\left(R_{t}^{e}\right) \simeq 7 \%$, and $\sigma\left(R_{t}^{e}\right) \simeq 18 \%$, which implies $\sigma\left(M_{t}\right) \geq 40 \%$. However, the annual standard deviation of changes in real exchange rates has been roughly $10 \%$ in the post-Bretton Woods period (see Table 8). Brandt, Cochrane, and Santa-Clara (2006) point out that this logic combined with equation (12) implies that $m_{t}$ and $m_{t}^{*}$ must be highly correlated — which is puzzling in standard models in which $m_{t}$ is proportional to consumption growth (which is not very correlated across countries).

Colacito and Croce (2011) point out that this puzzle, which they refer to as the "international equity premium puzzle," can be resolved in a long-run risks model where the long-run risk factors are

\footnotetext{
${ }^{30}$ Building on Alvarez and Jermann's (2005) analysis of the implication of the term structure for the properties of the stochastic discount factor, Koijen et al. (2010) emphasize that the positive autocorrelation of growth rates in the long-run risk model implies that the model has a downward sloping term structure of real bond yields.
} 
highly correlated across countries, even if transitory shocks are not. They consider the case where the long-run risk factors are perfectly correlated across countries, and show that this calibration generates realistic predictions for exchange rate volatility and the comovement of asset returns across countries. ${ }^{31}$

Our estimates of the world growth-rate and uncertainty processes speak directly to the strength of the low frequency correlation Colacito and Croce emphasize. The larger these world long-run risks are, the more correlated will be the stochastic discount factors in different countries (and therefore the less volatile will their real exchange rate be). Table 8 presents the standard deviation implied by our estimated model of annual changes in the bilateral real exchange rate versus the United State for each country in our sample. The table also presents a counter-factual for this statistic based on the same simulated data from our estimated model but ignoring the correlation between the stochastic discount factors of each country and the United States that is implied by our model - i.e., simply adding the variances of the two stochastic discount factors and taking a square root. We see that the presence of common long-run risk shocks in our model lowers the volatility of the real exchange rate by roughly a factor of two relative to what it would be if the stochastic discount factors were uncorrelated. Our model can therefore account for a large part of the discrepancy between the observed volatility of the real exchange rate and the volatility implied by a model in which marginal utility across countries is uncorrelated. Nevertheless, our estimates of the cross-country correlation in long-run risks suggest that long-run risks cannot fully resolve the international equity premium puzzle. ${ }^{32}$

\section{Intuition}

In this section, we provide intuition for the asset pricing results in our paper using the elegant decomposition developed by Borovicka, Hansen, and Scheinkman (2014, henceforth BHS). But let us begin by reviewing some basic asset pricing implications of our model for both stocks and bonds.

A positive growth-rate shock yields a large positive return on equity on impact (Figure 7).

\footnotetext{
${ }^{31}$ See also Lustig, Stathopoulus, and Verdelhan (2016) who argue based on long-term bond data that the permanent component of nominal stochastic discount facturs across countries are highly correlated.

${ }^{32}$ These results are relevant for our analysis of country-specific asset prices at the start of this section, in which we price assets using the stochastic discount factor of the domestic investor. If there were perfect risk-sharing, one could price the assets using foreign investors stochastic discount factors. However, as we discuss above, the complete markets view is at odds with the data, even accounting for an important common component of long-run risks. In view of this discrepancy, it makes sense to price the stock market using the local investor given the large amount of home bias in the data for both assets and goods.
} 
This positive return reflects the balance of two opposing forces. On the one hand, the shock raises expected future dividends on equity, which pushes up stock prices. On the other hand, since consumption growth is expected to be high for some time, agents' desire to save falls, which pushes down all asset prices. If agents are sufficiently willing to substitute consumption over time (i.e., the IES is sufficiently high), the first of these effects is stronger than the second for equity and the price of equity rises on impact. In the periods after the shock, returns on equity and the risk-free rate are higher than average because of agents' reduced desire to save.

A positive uncertainty shock yields a large negative return on equity on impact (Figure 8). As with the growth-rate shock, there are two opposing forces that together determine the response of stock prices. The increase in economic uncertainty makes stocks riskier, which raises the equity premium. This tends to depress the value of stock. However, the increase in uncertainty also increases the desire of agents to save. This tends to raise the price of all assets. For sufficiently high risk aversion and willingness to substitute consumption over time, the first force is stronger than the second and the price of stocks falls on impact when uncertainty rises (Campbell, 1993). In the periods after the shock, the equity premium remains elevated because uncertainty has risen.

\subsection{Shock Elasticities}

An equity claim can be thought of as a portfolio of claims to the dividends that the equity claim will yield at each horizon (a portfolio of "equity strips"), it is also useful to understand how sensitive the dividends, prices, and returns on each of these equity strips are to the different shocks that drive consumption growth in our model. BHS introduce the concepts of shock-exposure, shock-cost, and shock-price elasticities for this purpose. To illustrate these concepts, let's consider shock elasticities for the world growth-rate shock $\epsilon_{W, t+1}$ (elasticities for other shocks are defined analogously).

The shock-exposure elasticity at horizon $k$ then measures the elasticity of the level of expected dividends at time $t+k$ with respect to exposure to the world growth rate shock in period $t+1$ :

$$
\left.S E E_{t, t+k} \equiv \frac{d}{d r} \log \mathbb{E}_{t}\left[\exp \left(d_{t+k}+r \frac{\epsilon_{W, t+1}}{\sigma_{W, t}}-\frac{1}{2} r^{2}\right)\right]\right|_{r=0}=\frac{1}{\sigma_{W, t}} \frac{\mathbb{E}_{t}\left[D_{t+k} \epsilon_{W, t+1}\right]}{\mathbb{E}_{t} D_{t+k}}
$$

where $D_{t+k}=\exp \left(d_{t+k}\right)$ is the level of dividends at time $t+k$.

The shock-cost elasticity at horizon $k$ measures the elasticity of the level of the period $t$ price of the time $t+k$ equity strip with respect to exposure to the world growth rate shock. The expression for the shock-cost elasticity is analogous to that for the shock-exposure elasticity except that $d_{t+k}$ is replaced by $m_{t, t+k}+d_{t+k}$, where $m_{t, t+k}$ denotes the logarithm of the stochastic discount factor from 
period $t$ to period $t+k$. Finally, the shock-price elasticity is difference between the two elasticities defined above. Intuitively, this is the elasticity of the expected $k$ period return (between period $t$ and $t+k$ ) on the time $t+k$ equity strip with respect to exposure to the world growth rate shock. In appendix $\mathrm{C}$ we present expressions for the shock-cost and shock-price elasticity, as well as an alternative derivation that is useful for intuition.

Figure 9 plots the shock-exposure and shock-price elasticities (i.e., the elasticity of dividends and returns, respectively) with respect to the four long-run risk shocks in our model: the growth rate shocks, $\epsilon_{i, t+1}$ and $\epsilon_{W, t+1}$, and the volatility shocks, $\omega_{i, t+1}$, and $\omega_{W, t+1}$, evaluated at the model's steady state. The shock-exposure elasticities are plotted on the left and the shock-price elasticities are plotted on the right.

Let's begin by discussing the shock-exposure elasticities. All four shock-exposure elasticities start at zero. This is because the $t+1$ shocks have no effect on time $t+1$ dividends. The shock-exposure elasticities for the two growth-rate shocks then grow over time as the effect of the shock on the level of dividends grows. The shock-exposure elasticity plateaus much earlier for the idiosyncratic than the world growth rate shock, because of the greater persistence of the world growth-rate shock.

These increasing shock-exposure elasticities are ultimately the source of the upward sloping term structure of real yields implied by the long-run risks model. Koijen et al. (2010) emphasize that this feature of the model appears inconsistent with empirical evidence on dividend strip prices, which suggest a downward sloping real term structure. The inclusion of disaster risk in the asset pricing exercise is likely to improve the fit of the model to the asset pricing data in this regard, since rare disasters are partially mean reverting and therefore can generate a downward-sloping real term premium, as emphasized by Nakamura, et al. (2010).

In contrast to the standard long-run risks model, the shock-exposure elasticities for uncertainty fall over time (in response to a positive shock). The difference versus the standard model (which implies an increasing profile) arises from the correlation between growth rate and uncertainty shocks in our model: positive uncertainty shocks tend to occur in conjunction with negative growth rate shocks, leading to a negative shock-exposure elasticity. ${ }^{33}$

Turning to the shock-price elasticities (the elasticity of returns) plotted on the right-hand side of Figure 9, we see that both growth-rate shocks have a positive shock price elasticity starting in

\footnotetext{
${ }^{33}$ The shock-exposure elasticity to an uncertainty shock is positive in the standard model because the uncertainty shocks in the long-run risk model are shocks to uncertainty regarding log dividends, which has a level effect on dividends themselves.
} 
period 1; and uncertainty shocks have a negative shock-price elasticity starting in period 1. In both cases, the shock-price elasticities are essentially constant as the horizon increases. This arises even though the shock-exposure elasticities are steeply sloped and zero in period 1. The flat shock-price elasticities arise from the nature of Epstein-Zin-Weil preferences, as discussed in BHS. Intuitively, this is a consequence of the effect of future expectations on the current stochastic discount factor.

We can use the relative magnitude of the shock-price elasticities for the different long-run risk shocks to infer their relative importance for asset pricing. The most important shocks from the perspective of the shock-price elasticities are the world growth-rate and world uncertainty shocks. The world growth-rate shock has a shock-price elasticity roughly twice as large as the idiosyncratic growth-rate shock. The world uncertainty shock has a shock-price elasticity roughly four times as large as the idiosyncratic uncertainty shock. This difference arises because of the much greater persistence of the world growth-rate shocks relative to the idiosyncratic growth rate shocks. The world uncertainly shocks determine the volatility of these highly persistent world growth rate shocks; and therefore also have a large effect on asset pricing.

\section{Conclusion}

Our paper represents the first estimation of the long-run risks model based on macroeconomic data alone. We find evidence for both persistent growth rate and volatility shocks - the key features of the model. We show that it is crucial to distinguish between world and country-specific shocks, since world shocks are far more persistent than their idiosyncratic counterparts. In addition, we estimate a robust negative correlation between volatility and growth rate shocks, and a much larger volatility of long run risks shocks than conventional calibrations.

We next investigate the asset pricing implications of the model. An advantage of our estimation approach based on macroeconomic data alone is that the parameter estimates cannot be viewed as "backward engineered" to fit the asset pricing data. We emphasize three main results. First, our model explains a substantial fraction of cross-country variation in the equity premium. Second, our model generates more predictability of excess returns than conventional calibrations (in line with the data) but also more consumption growth predictability (not in line with the data).Third, our model endogenously generates a large volatility of the price-dividend ratios.

There are numerous ways in which our analysis could be extended. First, we do not consider the implications of parameter uncertainty. Given the difficulty of accurately estimating the long-run 
risks parameters, there is no doubt that parameter uncertainty is large, and likely to substantially increase the risk perceived by agents in the economy (see, e.g., Weitzman, 2007). Second, our analysis assesses the asset pricing importance of long-run risks, as opposed to the combination of long-run risks and disasters. Adding disaster risk would increase the amount of risk, and would likely help fit other features of the asset pricing data that the long-run risk misses, such as the downwardsloping profile of real yields (Nakamura, et al., 2010). Though computationally challenging, we view these as important topics for future research. Finally, for simplicity, our model assumes permanently different average growth rates for different countries. An interesting extension would be to allow for convergence towards the frontier country or conditional convergence dynamics. 


\section{A Model Estimation}

We employ a Bayesian MCMC algorithm to estimate our model. More specifically, we employ a Metropolized Gibbs sampling algorithm to sample from the joint posterior distribution of the unknown parameters and variables conditional on the data. The full probability model we employ may be denoted by

$$
f(Y, X, \Theta)=f(Y, X \mid \Theta) f(\Theta),
$$

where $Y=\left\{c_{i, t}, I_{i, t+1}^{d}\right\}$ is the set of observable variables for which we have data,

$$
X=\left\{\tilde{c}_{i, t}, x_{i, t}, x_{W, t}, \sigma_{i, t+1}^{2}, \sigma_{W, t+1}^{2}\right\}
$$

is the set of unobservable variables, and

$$
\Theta=\left\{\rho, \rho_{W}, \gamma, \sigma_{W}^{2}, \sigma_{\omega}^{2}, \sigma_{W, \omega}^{2}, \lambda, \lambda_{W}, \xi_{i}, \chi_{i}, \sigma_{i}^{2}, \sigma_{\nu, i}^{2}, \mu_{i}, \mu_{d},\right\}
$$

is the set of parameters. From a Bayesian perspective, there is no real importance to the distinction between $X$ and $\Theta$. The only important distinction is between variables that are observed and those that are not. The function $f(Y, X \mid \Theta)$ is often referred to as the likelihood function of the model, while $f(\Theta)$ is often referred to as the prior distribution. Both $f(Y, X \mid \Theta)$ and $f(\Theta)$ are fully specified in sections 3 and 4 of the paper. The likelihood function may be constructed by combining equations (1)-(3) and (8), the distributional assumptions for the shocks in these equations detailed in section 3 and the assumptions about the distributions of $\tilde{c}, x_{i, t}, x_{W, t}, \sigma_{i, t}$, and $\sigma_{W, t}$ for the initial period for each country that are detailed in section 4. The prior distributions are described in detail in section 4 .

The object of interest in our study is the distribution $f(X, \Theta \mid Y)$, i.e., the joint distribution of the unobservables conditional on the observed values of the observables. For expositional simplicity, let $\Phi=(X, \Theta)$. Using this notation, the object of interest is $f(\Phi \mid Y)$. The Gibbs sampler algorithm produces a sample from the joint distribution by breaking the vector of unknown variables into subsets and sampling each subvector sequentially conditional on the value of all the other unknown variables (see, e.g., Gelman et al., 2004, and Geweke, 2005). In our case we implement the Gibbs sampler as follows.

1. We derive the conditional distribution of each element of $\Phi$ conditional on all the other elements and conditional on the observables. For the $i$ th element of $\Phi$, we can denote this conditional distribution as $f\left(\Phi_{i} \mid \Phi_{-i}, Y\right)$, where $\Phi_{i}$ denotes the $i$ th element of $\Phi$ and $\Phi_{-i}$ 
denotes all but the $i$ th element of $\Phi$. In most cases, $f\left(\Phi_{i} \mid \Phi_{-i}, Y\right)$ are common distributions such as normal distributions or gamma distributions for which samples can be drawn in a computationally efficient manner. In cases where the Gibbs sampler cannot be applied, we use the Metropolis algorithm to sample values of $f\left(\Phi_{i} \mid \Phi_{-i}, Y\right) \cdot{ }^{34}$

2. We propose initial values for all the unknown variables $\Phi$. Let $\Phi^{0}$ denote these initial values.

3. We cycle through $\Phi$ sampling $\Phi_{i}^{t}$ from the distribution $f\left(\Phi_{i} \mid \Phi_{-i}^{t-1}, Y\right)$ where

$$
\Phi_{-i}^{t-1}=\left(\Phi_{1}^{t}, \ldots, \Phi_{i-1}^{t}, \Phi_{i+1}^{t-1}, \ldots, \Phi_{d}^{t-1}\right)
$$

and $d$ denotes the number of elements in $\Phi$. At the end of each cycle, we have a new draw $\Phi^{t}$. We repeat this step $N$ times to get a sample of $N$ draws for $\Phi$.

4. It has been shown that samples drawn in this way converge to the distribution $f(\Phi \mid Y)$ under very general conditions (see, e.g., Geweke, 2005). We assess convergence and throw away an appropriate burn-in sample.

In practice, we run four such "chains" starting two from one set of initial values and two from another set of initial values. We choose starting values that are far apart in the following way: For one chain, we set the initial values of $x_{i, t}=0$ for all $i$ and $t$. For the other chain, we set the initial values of $x_{i, t}=\Delta c_{i, t}$ for all $i$ and $t$.

Given a sample from the joint distribution $f(\Phi \mid Y)$ of the unobserved variables conditional on the observed data, we can calculate any statistic of interest that involves $\Phi$. For example, we can calculate the mean of any element of $\Phi$ by calculating the sample analogue of the integral

$$
\int \Phi_{i} f\left(\Phi_{i} \mid \Phi_{-i}^{t-1}, Y\right) d \Phi_{i}
$$

\footnotetext{
${ }^{34}$ The Metropolis algorithm samples a proposal $\Phi_{i}^{*}$ from a proposal distribution $J_{t}\left(\Phi_{i}^{*} \mid \Phi_{i}^{t-1}\right)$. This proposal distribution must be symmetric, i.e., $J_{t}\left(x_{a} \mid x_{b}\right)=J_{t}\left(x_{b} \mid x_{a}\right)$. The proposal is accepted with probability $\min (r, 1)$ where $r=f\left(\Phi_{i}^{*} \mid \Phi_{-i}, Y\right) / f\left(\Phi_{i}^{t-1} \mid \Phi_{-i}, Y\right)$. If the proposal is accepted, $\Phi_{i}^{t}=\Phi_{i}^{*}$. Otherwise $\Phi_{i}^{t}=\Phi_{i}^{t-1}$. Using the Metropolis algorithm to sample from $f\left(\Phi_{i} \mid \Phi_{-i}, Y\right)$ is much less efficient than the standard algorithms used to sample from known distributions such as the normal distribution in most software packages. Intuitively, this is because it is difficult to come up with an efficient proposal distribution. The proposal distribution we use is a normal distribution centered at $\Phi_{i}^{t-1}$.
} 


\section{B Variance Ratios}

Variance ratios are a simple tool to quantify the persistence of shocks to aggregate consumption (Cochrane, 1988). The $k$-period variance ratio for consumption growth is defined as the ratio of the variance of $k$-period consumption growth and 1-period consumption growth divided by $k$ :

$$
\mathrm{VR}_{i, k}=\frac{1}{k} \frac{\operatorname{var}\left(\sum_{j=0}^{k-1} \Delta c_{i, t-j}\right)}{\operatorname{var}\left(\Delta c_{i, t}\right)} .
$$

The intuition for this statistic comes from the fact that for a simple random-walk process $\operatorname{var}\left(c_{i, t}-\right.$ $\left.c_{i, t-k}\right)$ is equal to $k$ times $\operatorname{var}\left(c_{i, t}-c_{i, t-1}\right)$, implying that the variance ratio for such a process is equal to one for all $k$. For a trend-stationary process, the variance ratio is less than one and falls toward zero as $k$ increases. However, for a process that has persistent growth-rate shocks-i.e., positively autocorrelated growth rates - the variance ratio is larger than one.

Bansal and Yaron (2004) introduce a variance ratio statistic for assessing the persistence of shocks to volatility. They first compute the innovations to consumption growth $u_{i, t}$ as the residuals from an $\operatorname{AR}(5)$ regression and use the absolute value of these innovations $\left|u_{i, t}\right|$ as a measure of realized volatility of consumption growth. They then construct variance ratios for $\left|u_{i, t}\right|$,

$$
\mathrm{VR}_{i, k}^{u}=\frac{1}{k} \frac{\operatorname{var}\left(\sum_{j=0}^{k-1}\left|u_{i, t-j}\right|\right)}{\operatorname{var}\left(\left|u_{i, t}\right|\right)} .
$$

This statistic provides a rough measure of the persistence of stochastic volatility. As with the variance ratio for consumption growth, if this variance ratio is above one, it indicates that uncertainty shocks have persistent effects on volatility-i.e., high volatility periods are "bunched together" leading to a high value of the variance in the numerator. 


\section{Shock Elasticities}

The shock-cost elasticity at horizon $k$ for the world growth-rate shock is

$$
\left.S C E_{t, t+k} \equiv \frac{d}{d r} \log \mathbb{E}_{t}\left[\exp \left(m_{t, t+k}+d_{t+k}+r \frac{\epsilon_{W, t+1}}{\sigma_{W, t}}-\frac{1}{2} r^{2}\right)\right]\right|_{r=0}=\frac{1}{\sigma_{W, t}} \frac{\mathbb{E}_{t}\left[M_{t, t+k} D_{t+k} \epsilon_{W, t+1}\right]}{\mathbb{E}_{t}\left[M_{t, t+k} D_{t+k}\right]}
$$

The shock-price elasticity at horizon $k$ for the world growth-rate shock is

$$
S P E_{t, t+k} \equiv S E E_{t, t+k}-S C E_{t, t+k}=\frac{1}{\sigma_{W, t}} \frac{\mathbb{E}_{t}\left[D_{t+k} \epsilon_{W, t+1}\right]}{\mathbb{E}_{t} D_{t+k}}-\frac{1}{\sigma_{W, t}} \frac{\mathbb{E}_{t}\left[M_{t, t+k} D_{t+k} \epsilon_{W, t+1}\right]}{\mathbb{E}_{t}\left[M_{t, t+k} D_{t+k}\right]} .
$$

It is useful to develop an alternative way of deriving the shock elasticities. For concreteness, let's consider the shock-exposure elasticity for horizon $k$ and for the world growth-rate shock. The distribution of the world growth rate shock divided by its standard deviation is $\epsilon_{W, t+1} / \sigma_{W, t} \sim \mathrm{N}(0,1)$. Let's denote cumulative distribution of $\epsilon_{W, t+1} / \sigma_{W, t}$ by $Q\left(\epsilon_{W, t+1} / \sigma_{W, t}\right)$. Now, let's contemplate the notion that the distribution of $\epsilon_{W, t+1} / \sigma_{W, t}$ is perturbed and becomes $\epsilon_{W, t+1} / \sigma_{W, t} \sim \mathrm{N}(r, 1)$. In other words, its mean increases by $r$. Let's denote the cumulative distribution of this alternative distribution by $Q^{r}\left(\epsilon_{W, t+1} / \sigma_{W, t}\right)$. Intuitively, if the distribution of $\epsilon_{W, t+1} / \sigma_{W, t}$ changes from $Q\left(\epsilon_{W, t+1} / \sigma_{W, t}\right)$ to $Q^{r}\left(\epsilon_{W, t+1} / \sigma_{W, t}\right)$, the economy will get hit by a larger value of $\epsilon_{W, t+1} / \sigma_{W, t}$ on average.

Let $X_{t}$ denote the state of the economy at time $t$. Consider the expected dividend in period $t+k$ conditional on information at time $t$ and also conditional on a particular value $\epsilon$ for the world growth-rate shock at time $t+1$

$$
\Phi_{t, t+k}(\epsilon) \equiv \mathbb{E}\left[D_{t+k} \mid X_{t}=x, \epsilon_{W, t+1} / \sigma_{W, t}=\epsilon\right]
$$

Finally, consider the following generalized impulse response function

$$
\operatorname{GIRF}^{r}(x) \equiv \log \int \Phi_{t, t+k}(\epsilon) d Q^{r}(\epsilon)-\log \int \Phi_{t, t+k}(\epsilon) d Q(\epsilon)
$$

This is the difference between the $\log$ of $\Phi_{t, t+k}(\epsilon)$ averaged across $\epsilon$ under the perturbed distribution and under the unperturbed distribution. The shock-exposure elasticity is then defined as

$$
\left.\frac{d}{d r}\left[G I R F_{t, t+k}^{r}\right]\right|_{r=0}=\frac{\int \Phi_{t, t+k}(\epsilon) \epsilon d Q(\epsilon)}{\int \Phi_{t, t+k}(\epsilon) d Q(\epsilon)} .
$$




\section{References}

Abel, A. B. (1999): "Risk Premia and Term premia in General Equilibrium," Journal of Monetary Economics, 43, 3-33.

Aguiar, M., and G. Gopinath (2007): "Emerging Market Business Cycles: The Cycle Is the Trend," Journal of Political Economy, 115(1), 69-102.

Alvarez, F., and U. J. Jermann (2005): "Using Asset Prices to Measure the Persistence of the Marginal Utility of Wealth," Econometrica, 73(6), 1977-2016.

Ang, A., And G. Bekaert (2007): "Stock Return Predictability: Is it There?," Review of Financial Statistics, 20(3), 651-707.

Balke, N. S., And R. J. Gordon (1989): "The Estimation of Prewar Gross National Product: Methodology and New Evidence," Journal of Political Economy, 97, 38-92.

Bansal, R., R. F. Dittmar, and C. T. Lundblad (2005): "Consumption, Dividends, and the Cross Section of Equity Returns," Journal of Finance, 60(4), 1639-1672.

Bansal, R., V. Khatchatrian, and A. Yaron (2005): "Interpretable Asset Markets?," European Economic Review, 49, 531-560.

Bansal, R., D. Kiku, and A. Yaron (2007): "Risks For the Long Run: Estimation and Inference," Working Paper, Duke University.

(2012): "An Empirical Evaluation of the Long-Run Risks Model for Asset Prices," Critical Finance Review, 1, 183-221.

Bansal, R., And I. Shaliastovich (2010): "A Long-Run Risks Explanation of Predictability Puzzles in Bond and Currency Markets," Working Paper, Duke University.

Bansal, R., and A. Yaron (2004): "Risks for the Long Run: A Potential Resolution of Asset Pricing Puzzles," Journal of Finance, 59(4), 1481-1509.

Barro, R. (2006): "Rare Disasters and Asset Markets in the Twentieth Century," Quarterly Journal of Economics, 121(3), 832-866.

Barro, R. J., And J. F. Ursua (2008): "Macroeconomic Crises since 1870," Brookings Papers on Economic Activity, 2008, 255-350.

Barsky, R. B., F. T. Juster, M. S. Kimball, and M. D. Shapiro (1997): "Preference Parameters and Behavioral Heterogeneity: An Experimental Approach in the Health and Retirement Study," Quarterly Journal of Economics, 112(2), 537-579.

Basu, S., And B. Bundick (2011): "Uncertainty Shocks in a Model of Effective Demand," Working Paper, Boston College.

Beeler, J., and J. Y. Campbell (2012): "The Long-Run Risk Model and Aggregate Asset Prices: An Empirical Assessment," Critical Finance Review, 1, 141-182.

Bidder, R., And M. E. Smith (2010): "Doubts and Variability," Working Paper. 
Binsbergen, J. H., M. W. Brandt, and R. S. Koijen (2012): "On the Timing and Pricing of Dividends," American Economic Review, 102(4), 1596-1618.

Binsbergen, J. H., and R. S. J. Koijen (2010): "Predictive Regressions: A Present-Value Approach," Journal of Finance, 65(4), 1439-1471.

Blanchard, O., and J. Simon (2001): "The Long and Large Decline in U.S. Output Volatility," Brookings Papers on Economic Activity, 2001(1), 135-164.

Bloom, N. (2009): "The Impact of Uncertainty Shocks," Econometrica, 77(3), 623-685.

Bloom, N., M. Floetotto, N. Jaimovich, I. Saporta-Eksten, and S. Terry (2011): "Really Uncertain Business Cycles," Working Paper, Stanford University.

Bonomo, M., R. Garcia, N. Meddahi, and R. Tedongap (2011): "Generalized Disappointment Aversion, Long-run Volatility Risk, and Asset Prices," Review of Financial Studies, 24(1), $83-122$.

Borovicka, J., L. P. Hansen, M. Hendricks, and J. A. Scheinkman (2011): "Risk-Price Dynamics," Journal of Financial Econometrics, 9(1), 3-65.

Borovicka, J., L. P. Hansen, and J. A. Scheinkman (2014): "Shock Elasticities and Impulse Responses," Mathematics and Financial Economics, 8(4), 333-354.

Brandt, M. W., J. H. Cochrane, and P. Santa-Clara (2006): "International Risk Sharing Is Better than You Think, or Exchange Rates Are too Smooth," Journal of Monetary Economics, 53, 671-698.

Campbell, J. Y. (1993): "Intertemporal Asset Pricing without Consumption Data," American Economic Review, 83(3), 487-512.

Campbell, J. Y., and J. H. Cochrane (1999): "By force of habit: A consumption-based explanation of aggregate stock market behavior," Journal of Political Economy, 107, 205-251.

Campbell, J. Y., and N. G. Mankiw (1989): "International Evidence on the Persistence of Economic Fluctuations," Journal of Monetary Economics, 23, 319-333.

Campbell, J. Y., and R. J. Shiller (1988): "The Dividend-Price Ratio and Expectations of Future Dividends and Discount Factors," The Review of Financial Studies, 1(3), 195-228.

Chetty, R. (2006): "A New Method of Estimating Risk Aversion," American Economic Review, 96(5), 1821-1834.

Cochrane, J. H. (1988): "How Big Is the Random Walk in GNP?," Journal of Political Economy, 96(5), 893-920.

(2008): "The Dog That Did Not Bark: A Defense of Return Predictability," Review of Financial Studies, 21(4), 1533-1575.

Cogley, T. (1990): "International Evidence on the Size of the Random Walk in Output," Journal of Political Economy, 98(3), 501-518. 
Colacito, R., and M. M. Croce (2011): "Risks for the Long-Run and the Real Exchange Rate," Journal of Political Economy, 119(1), 153-181.

Collin-Dufresne, P., M. Johannes, and L. A. Lochstoer (2012): "Parameter Learning in General Equilibrium: The Asset Pricing Implications," Working Paper, Columbia University.

Constantinides, G., And D. Duffie (1996): "Asset Pricing with heterogeneous consumers," Journal of Political Economy, 104(2), 219-240.

Constantinides, G. M., and A. Ghosh (2011): "Asset Pricing Tests with Long-Run Risks in Consumption Growth," Review of Asset Pricing Studies, 1, 96-136.

Croce, M. M., M. Lettau, and S. C. Ludvigson (2010): "Investor Information, Long-Run Risk, and the Duration of Risky Cash Flows," Working Paper, UNC, Chapel Hill.

Epstein, L. G., And S. E. Zin (1989): "Substitution, Risk Aversion and the Temporal Behavior of Consumption and Asset Returns," Econometrica, 57, 937-969.

Fama, E. F., And K. R. French (1988): "Dividend Yields and Expected Stock Returns," Journal of Financial Economics, 22, 3-27.

Fernandez-Villaverde, J., P. Guerron-Quintana, J. Rubio-Ramirez, and M. Uribe (2011): "Risk Matters: The Real Effects of Volatility Shocks," American Economic Review, 101, $2530-2561$.

Garleanu, N., and S. Panageas (2010): "Young, Old, Conservative and Bold. The Implications of Finite Lives and Heterogeneity for Asset Pricing," Working Paper, University of Chicago.

Gelman, A., J. B. Carlin, H. S. Stern, and D. B. Rubin (2004): Bayesian Data Analysis. John Wiley and Sons, Hoboken, New Jersey.

Gelman, A., And D. B. Rubin (1992): "Inference from Iterative Simulation Using Multiple Sequences," Statistical Science, 7, 457-511.

Geweke, J. (2005): Contemporary Bayesian Econometrics and Statistics. Chapman \& Hall/CRC, Boca Raton, Florida.

Hansen, L. P. (2007): "Beliefs, Doubts and Learning: Valuing Macroeconomic Risk," American Economic Review, 97(2), 1-30.

Hansen, L. P., J. C. Heaton, and N. Li (2008): "Consumption Strikes Back? Measuring Long-Run Risk," Journal of Political Economy, 116(2), 260-302.

Hansen, L. P., and R. Jagannathan (1991): "Implications of Security Market Data for Models of Dynamic Economies," Journal of Political Economy, 99, 225-262.

Hansen, L. P., And T. J. Sargent (2010): "Fragile Beliefs and the Price of Uncertainty," Quantitative Economics, 1(1), 129-162.

Hodrick, R. J. (1992): "Dividend Yields and Expected Stock Returns: Alternative Procedures for Inference and Measurement," Review of Financial Studies, 5(3), 357-386. 
Kaltenbrunner, G., and L. A. Lochstoer (2010): "Long-Run Risk through Consumption Smoothing," Review of Financial Studies, 23, 3141-3189.

Kandel, S., and R. F. Stambaugh (1990): "Expectations and Volatility of Consumption and Asset Returns," Review of Financial Studies, 3(2), 207-232.

Kilian, L., and L. E. Ohanian (2002): "Unit Roots, Trend Breaks, and Transitory Dynamics: A Macroeconomic Perspective," Macroeconomic Dynamics, 6(5), 614-632.

Koijen, R. S., H. Lustig, S. V. Nieumerburgh, and A. Verdelhan (2010): "Long Run Risk, the Wealth-Consumption Ratio, and the Temporal Pricing of Risk," American Economic Review, 100(2), 552-556.

Kung, H., And L. Schmid (2011): "Innovation, Growth, and Asset Pricing," Working Paper, Duke University.

Lettau, M., S. C. Ludvigson, and J. A. Wachter (2004): "The Declining Equity Premium: What Role Does Macroeconomic Risk Play," NBER Working Paper No. 10270.

(2008): "The Declining Equity Premium: What Role Does Macroeconomic Risk Play," The Review of Financial Studies, 21(4), 1653-1687.

Lewellen, J. W. (2004): "Fredicting Returns with Financial Ratios," Journal of Financial Economics, 74, 209-235.

Ludvigson, S. C. (2013): "Advances in Consumption-Based Asset Pricing: Empirical Tests," in Handbook of the Economics of Finance, ed. by M. H. George M. Constantinides, and R. M. Stulz, pp. 799-1612. Elseveir.

Lustig, H., A. Stathopoulus, and A. Verdelhan (2016): "Nominal Exchange Rate Stationarity and Long-Term Bond Returns," Working Paper, Standford University.

Malloy, C. J., T. J. Moskowitz, and A. Vissing-Jorgensen (2009): "Long-Run Stockholder Consumption Risk and Asset Returns," Journal of Finance, 64(6), 2427-2479.

McConnell, M. M., And G. Perez-Quiros (2000): "Output Fluctuations in the United States: What Has Changed since the Early 1980's," American Economic Review, 90(5), 1464-1476.

Mehra, R., and E. C. Prescott (1985): "The Equity Premium: A Puzzle," Journal of Monetary Economics, 15, 145-161.

Nakamura, E., J. Steinsson, R. Barro, and J. Ursua (2010): "Crises and Recoveries in an Empirical Model of Consumption Disasters," Working Paper, Columbia University.

Nelson, C. R., and C. I. Plosser (1982): "Trends and Random Walk in Macroeconomic Time Series: Some Evidence and Implications," Journal of Monetary Economics, 10, 139-162.

Paravisini, D., V. Rappoport, and E. Ravina (2010): "Risk Aversion and Wealth: Evidence from Person-to-Person Lending Portfolios," NBER Working Paper No. 16063.

Pastor, L., and P. Veronesi (2009): "Learning in Financial Markets," Annual Review of Financial Economics, 1, 361-381. 
Piazzesi, M., And M. Schneider (2006): "Equilibrium Yield Curves," in NBER Macroeconomics Annual, ed. by D. Acemoglu, K. Rogoff, and M. Woodford, pp. 389-442, Cambridge, Ma. MIT Press.

QuAh, D. (1992): "The Relative Importance of Permanent and Transitory Components: Identification and Some Theoretical Bounds," Econometrica, 60(1), 107-118.

Romer, C. D. (1986): "Is the Stabilization of the Postwar Economy a Figment of the Data," American Economic Review, 76(3), 314-334.

Stambaugh, R. F. (1999): "Predictive Regressions," Journal of Financial Economics, 54, 375421.

Stock, J. H., and M. W. Watson (2002): "Has the Business Cycle Changed and Why?," in NBER Macroeconomics Annual, ed. by M. Gertler, and K. Rogoff, pp. 159-218, Cambridge, MA. MIT Press.

Tallarini, T. D. (2000): "Risk-sensitive real business cycles," Journal of Monetary Economics, $45(3), 507-532$.

Timmermann, A. G. (1993): "How Learning in Financial Markets Generates Excess Volatility and Predictability of Stock Returns," Quarterly Journal of Economics, 108, 1135-1145.

Uhlig, H. (2007): "Leisure, Growth and Long Run Risk," Working Paper, University of Chicago.

Ursua, J. (2010): “Long-Run Volatility,” Working Paper, Harvard University.

Wachter, J. A. (2005): "A Consumption-Based Model of the Term Structure of Interest Rates," Journal of Financial Economics, 79, 365-399.

WeIL, P. (1990): "Nonexpected Utility in Macroeconomics," Quarterly Journal of Economics, $105(1), 29-42$.

Weitzman, M. L. (2007): "Subjective Expectations and Asset-Return Puzzles," American Economic Review, 97(4), 1102-1130. 
TABLE I

Estimates for Pooled Parameters

\begin{tabular}{|c|c|c|c|c|}
\hline & Prior & Baseline & Simple Model & Post-WWII \\
\hline \multicolumn{5}{|l|}{ Persistence: } \\
\hline Country-Specific Growth-Rate Shocks ( $\rho)$ & $\begin{array}{c}0.500 \\
(0.286)\end{array}$ & $\begin{array}{c}0.572 \\
(0.044)\end{array}$ & $\begin{array}{c}0.696 \\
(0.032)\end{array}$ & $\begin{array}{c}0.555 \\
(0.054)\end{array}$ \\
\hline World Growth-Rate Shocks $\left(\rho_{\mathrm{W}}\right)$ & $\begin{array}{c}0.500 \\
(0.286)\end{array}$ & $\begin{array}{c}0.922 \\
(0.045)\end{array}$ & -- & $\begin{array}{c}0.922 \\
(0.049)\end{array}$ \\
\hline Stochastic Volatility $(\gamma)$ & $\begin{array}{c}0.493 \\
(0.281)\end{array}$ & $\begin{array}{c}0.969 \\
(0.012)\end{array}$ & $\begin{array}{c}0.948 \\
(0.022)\end{array}$ & $\begin{array}{c}0.946 \\
(0.041)\end{array}$ \\
\hline \multicolumn{5}{|l|}{ Standard Deviations: } \\
\hline Country-Specific Stoch. Vol. Shock $\left(\sigma_{\omega}\right)$ & $\begin{array}{c}0.000033 \\
(0.000012)\end{array}$ & $\begin{array}{c}0.000025 \\
(0.000006)\end{array}$ & $\begin{array}{c}0.000042 \\
(0.000006)\end{array}$ & $\begin{array}{c}0.000031 \\
(0.000008)\end{array}$ \\
\hline World Stoch. Vol. Shock $\left(\sigma_{\omega, \mathrm{W}}\right)$ & $\begin{array}{c}0.000013 \\
(0.000005)\end{array}$ & $\begin{array}{c}0.000017 \\
(0.000003)\end{array}$ & -- & $\begin{array}{c}0.000016 \\
(0.000003)\end{array}$ \\
\hline Rel. St. Dev. of World Random Walk Shock $\left(\chi_{W}\right)$ & $\begin{array}{c}3.34 \\
(1.18)\end{array}$ & $\begin{array}{c}1.80 \\
(0.66)\end{array}$ & -- & $\begin{array}{c}1.59 \\
(0.68)\end{array}$ \\
\hline \multicolumn{5}{|l|}{ Correlations: } \\
\hline Country-Specific $(\lambda)$ & $\begin{array}{c}0.00 \\
(0.57)\end{array}$ & $\begin{array}{l}-0.47 \\
(0.17)\end{array}$ & -- & $\begin{array}{l}-0.45 \\
(0.23)\end{array}$ \\
\hline World $\left(\lambda_{\mathrm{W}}\right)$ & $\begin{array}{c}0.00 \\
(0.57)\end{array}$ & $\begin{array}{l}-0.42 \\
(0.24)\end{array}$ & -- & $\begin{array}{l}-0.47 \\
(0.27)\end{array}$ \\
\hline
\end{tabular}

The table reports prior and posterior means of the parameters with prior and posterior standard deviations in parentheses. The "Baseline" case is for our full model estimated on data from 1890-2009. The "Simple Model" case is for our simple model estimated on data from 1890-2009. The "Post-WWII" case is for our full model estimated on data from 1950-2009.

TABLE II

Estimates of Persistence and Volatility

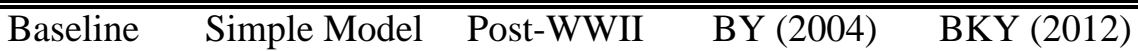

A. Persistence: (half-lives in years)

Country-Specific Growth-Rate Process $\left(\mathrm{x}_{\mathrm{i}, \mathrm{t}}\right)$

1.2

World Growth-Rate Process $\left(\mathrm{x}_{\mathrm{W}, \mathrm{t}}\right)$

8.5

1.9

1.2

2.7

2.3

Uncertainty Processes $\left(\sigma_{\mathrm{i}, \mathrm{t}}^{2}\right.$ and $\left.\sigma_{\mathrm{W}, \mathrm{t}}^{2}\right)$

22.0

12.9

8.5

12.6

4.4

$--$

B. Volatility (standard devation of consumption growth)

$\begin{array}{llllll}\text { Total } & 0.026 & 0.025 & 0.023 & 0.029 & 0.029 \\ \text { No growth-rate shocks (\% of baseline) } & 0.628 & 0.686 & 0.586 & 0.757 & 0.792 \\ \text { Stoch. Vol. fixed at 5th Quantile } & 0.007 & 0.006 & 0.005 & 0.023 & 0.009 \\ \text { Stoch. Vol. fixed at 50th Quantile } & 0.024 & 0.024 & 0.021 & 0.029 & 0.028 \\ \text { Stoch. Vol. fixed at 95th Quantile } & 0.038 & 0.036 & 0.032 & 0.034 & 0.045\end{array}$

The table reports measures of persistence and volatility for three versions of our model as well as for the model in Bansal and Yaron (2004) and Bansal, Kiku, and Yaron (2012). Panel A reports the persistence of the country-specific growth-rate process, the world growth-rate process, and the uncertainty processes in terms of the half-life in years. Panel B reports the standard deviation of consumption growth in a long simulation of several variants of each model. The first row (labeled "total") reports volatility of each model without any modification. The second row reports the volatility when the persistent growth-rate processes $\left(\mathrm{x}_{\mathrm{i}, \mathrm{t}}\right.$ and $\left.\mathrm{x}_{\mathrm{W}, \mathrm{t}}\right)$ are set to zero as a fraction of the total volatility in the baseline model. The third through fifth rows report the volatility of consumption growth in a version of each model where volatility is constant and set to the level of volatility that is the 5th, 50th and 95th quantiles of the distribution of stochastic volatility for the U.S. in that model. 
TABLE III

Estimates for Country-Specific Parameters

\begin{tabular}{|c|c|c|c|c|c|c|c|}
\hline & \multirow{2}{*}{ Prior } & \multicolumn{2}{|c|}{ Baseline } & \multicolumn{2}{|c|}{ Simple Model } & \multicolumn{2}{|c|}{ Post-WWII } \\
\hline & & Median & U.S. & Median & U.S. & Median & U.S. \\
\hline \multirow[t]{2}{*}{ Rel. St. Dev. of Random Walk Shock $\left(\chi_{\mathrm{i}}\right)$} & 3.38 & 0.88 & 1.06 & 0.98 & 1.20 & 0.89 & 0.84 \\
\hline & $(1.18)$ & $(0.43)$ & $(0.41)$ & $(0.48)$ & $(0.54)$ & $(0.45)$ & $(0.39)$ \\
\hline \multirow[t]{2}{*}{ Sensitivity to Common Shocks $\left(\xi_{\mathrm{i}}\right)$} & 0.500 & 0.59 & 0.61 & -- & -- & 0.63 & 0.62 \\
\hline & $(0.289)$ & $(0.14)$ & $(0.15)$ & -- & -- & $(0.14)$ & $(0.16)$ \\
\hline \multirow[t]{2}{*}{ Average Growth $\left(\mu_{\mathrm{i}}\right)$} & 0.015 & 0.014 & 0.015 & 0.015 & 0.018 & 0.016 & 0.017 \\
\hline & $(0.030)$ & $(0.005)$ & $(0.005)$ & $(0.004)$ & $(0.004)$ & $(0.006)$ & $(0.006)$ \\
\hline \multicolumn{8}{|l|}{ Standard Deviations: } \\
\hline \multirow[t]{2}{*}{ Average Stochastic Volatility $\left(\sigma_{\mathrm{i}}\right)$} & 0.0133 & 0.0087 & 0.0081 & 0.0113 & 0.0110 & 0.0080 & 0.0083 \\
\hline & $(0.0047)$ & $(0.0036)$ & $(0.0034)$ & $(0.0037)$ & $(0.0039)$ & $(0.0037)$ & $(0.0035)$ \\
\hline \multirow[t]{2}{*}{ Post-1945 Transitory Shock $\left(\sigma_{v i}\right)$} & 0.0067 & 0.0036 & 0.0024 & 0.0041 & 0.0037 & 0.0034 & 0.0023 \\
\hline & $(0.0023)$ & $(0.0016)$ & $(0.0015)$ & $(0.0020)$ & $(0.0020)$ & $(0.0016)$ & $(0.0013)$ \\
\hline \multirow[t]{2}{*}{ Pre-1945 Transitory Shock $\left(\sigma_{v i}\right)$} & 0.0667 & 0.0230 & 0.0232 & 0.0227 & 0.0236 & -- & -- \\
\hline & $(0.0236)$ & $(0.0046)$ & $(0.0046)$ & $(0.0048)$ & (0.0049) & -- & -- \\
\hline
\end{tabular}

The table reports prior and posterior means of the parameters with prior and posterior standard deviations in parentheses. The "Baseline" case is for our full model estimated on data from 1890-2009. The "Simple Model" case is for our simple model estimated on data from 1890-2009. The "Post-WWII" case is for our full model estimated on data from 1950-2009. "Median" refers to the median value of the statistic in question -- mean or standard deviation -- across the countries. 
TABLE IV

Properties of Consumption Growth

\begin{tabular}{|c|c|c|c|c|c|c|}
\hline & \multicolumn{3}{|c|}{ Median Country } & \multicolumn{3}{|c|}{ United States } \\
\hline & \multirow{2}{*}{ Data } & \multicolumn{2}{|c|}{ Model } & \multirow{2}{*}{ Data } & \multicolumn{2}{|c|}{ Model } \\
\hline & & Median & {$[2.5 \%, 97.5 \%]$} & & Median & {$[2.5 \%, 97.5 \%]$} \\
\hline $\mathrm{AC}(1)$ & 0.12 & -0.01 & {$[-0.17,0.17]$} & -0.08 & -0.05 & {$[-0.33,0.25]$} \\
\hline $\mathrm{AC}(2)$ & 0.13 & 0.13 & {$[0.03,0.27]$} & 0.16 & 0.14 & {$[-0.08,0.40]$} \\
\hline $\mathrm{AC}(3)$ & 0.04 & 0.10 & {$[0.01,0.25]$} & -0.21 & 0.09 & {$[-0.11,0.36]$} \\
\hline $\mathrm{AC}(4)$ & 0.09 & 0.07 & {$[-0.01,0.22]$} & 0.28 & 0.09 & {$[-0.15,0.34]$} \\
\hline $\mathrm{AC}(5)$ & 0.01 & 0.06 & {$[-0.02,0.20]$} & -0.09 & 0.08 & {$[-0.19,0.29]$} \\
\hline $\mathrm{AC}(10)$ & 0.12 & 0.02 & {$[-0.05,0.13]$} & 0.11 & 0.02 & {$[-0.21,0.21]$} \\
\hline $\operatorname{VR}(15) \Delta \mathrm{C}$ & 1.53 & 1.33 & {$[0.77,3.08]$} & 1.29 & 1.39 & {$[0.44,3.89]$} \\
\hline VR(15) Vol & 2.10 & 1.93 & {$[1.22,3.05]$} & 1.80 & 2.12 & {$[0.74,4.61]$} \\
\hline CrossC(1) & 0.21 & 0.15 & {$[0.08,0.30]$} & 0.18 & 0.16 & {$[0.03,0.34]$} \\
\hline CrossC(5) & 0.43 & 0.36 & {$[0.14,0.61]$} & 0.43 & 0.38 & {$[0.11,0.67]$} \\
\hline CrossC(10) & 0.55 & 0.45 & {$[0.15,0.77]$} & 0.54 & 0.47 & {$[0.06,0.79]$} \\
\hline
\end{tabular}

The table reports autocorrelations, cross-country correlations and variance ratios for the real-world data and simulated data from the model (excluding disasters in both cases). The first through sixth rows present the autocorrelation of one year through five year and ten year consumption growth. The next three rows present cross-country correlations of one, five and ten year consumption growth. The last two rows present the fifteen year variance ratio of consumption growth and the realized volatility of consumption growth. For the cross-country correlations, the median country results are the median of the 120 cross-country correlations across our 16 countries. For the results based on data from the model, we simulate 1000 datasets from the model of the same size as the actual data. For each such simulation we calculate the median across countries as well as the value for the U.S. for each statistic. We then report the median along with the $2.5 \%$ and $97.5 \%$ quantiles across simulations for each of these statistic.

TABLE V

Asset Pricing Statistics

\begin{tabular}{lcccc}
\hline \hline & \multicolumn{2}{c}{ Data } & \multicolumn{2}{c}{ Baseline Model } \\
& Median & U.S. & Median & U.S. \\
\hline $\mathrm{E}\left(\mathrm{R}_{\mathrm{m}}-\mathrm{R}_{\mathrm{f}}\right)$ & 6.87 & 7.10 & 6.99 & 7.23 \\
$\sigma\left(\mathrm{R}_{\mathrm{m}}-\mathrm{R}_{\mathrm{f}}\right)$ & 21.82 & 17.37 & 13.46 & 13.46 \\
$\mathrm{E}\left(\mathrm{R}_{\mathrm{m}}-\mathrm{R}_{\mathrm{f}}\right) / \sigma\left(\mathrm{R}_{\mathrm{m}}-\mathrm{R}_{\mathrm{f}}\right)$ & 0.32 & 0.41 & 0.52 & 0.54 \\
$\mathrm{E}\left(\mathrm{R}_{\mathrm{m}}\right)$ & 9.10 & 8.23 & 8.20 & 8.47 \\
$\sigma\left(\mathrm{R}_{\mathrm{m}}\right)$ & 21.99 & 17.89 & 13.45 & 13.46 \\
$\mathrm{E}\left(\mathrm{R}_{\mathrm{f}}\right)$ & 1.43 & 1.13 & 1.12 & 1.24 \\
$\sigma\left(\mathrm{R}_{\mathrm{f}}\right)$ & 4.57 & 3.33 & 1.53 & 1.54 \\
\hline $\mathrm{E}(\mathrm{p}-\mathrm{d})$ & 3.30 & 3.30 & 2.84 & 2.83 \\
$\sigma(\mathrm{p}-\mathrm{d})$ & 0.41 & 0.40 & 0.26 & 0.26 \\
$\mathrm{AC} 1(\mathrm{p}-\mathrm{d})$ & 0.85 & 0.90 & 0.89 & 0.89 \\
\hline
\end{tabular}

Columns labeled as "Median" report the result for the median country for each statistic. Columns labeled as "U.S." report these statistics for the United States. The first two columns are estimates from real world data from non-disaster years. We use total nominal returns and dividend-price ratios on stock from GFD and total real returns on government bills and inflation rates from Barro and Ursua (2008). The second two columns are based on data from our baseline model. For returns the statistics we report are the unconditional average of the level of the ex-post real net return in percentage points (i.e., multiplied by 100 ). $\mathrm{R}_{\mathrm{m}}$ denotes the return on equity (the market), while $\mathrm{R}_{\mathrm{f}}$ denotes the return on a short term nominal government bond (risk-free rate). The last three rows report statistics for the logarithm of the price-dividend ratio on equity. For the model, these results are for a CRRA $=9, \mathrm{IES}=1.5$, and subjective discount factor of $\beta=0.99$, and are calculated using a sample of length 1 million years. 
TABLE VI

The Equity Premium and Risk-Free Rate Across Countries and Models

\begin{tabular}{lcccc|cc}
\hline \hline & \multicolumn{3}{c|}{ Equity Premium } & \multicolumn{2}{c}{ Risk-Free Rate } \\
& Data & $\begin{array}{c}\text { Full } \\
\text { Model }\end{array}$ & $\begin{array}{c}\text { Constant } \\
\text { Volatility }\end{array}$ & $\begin{array}{c}\text { Mehra- } \\
\text { Prescott }\end{array}$ & Data & $\begin{array}{c}\text { Full } \\
\text { Model }\end{array}$ \\
\hline Australia & 0.087 & 0.057 & 0.023 & 0.010 & 0.011 & 0.012 \\
Belgium & 0.081 & 0.079 & 0.028 & 0.005 & 0.014 & 0.007 \\
Canada & 0.065 & 0.065 & 0.028 & 0.014 & 0.013 & 0.013 \\
Denmark & 0.046 & 0.061 & 0.026 & 0.007 & 0.029 & 0.013 \\
Finland & 0.128 & 0.116 & 0.053 & 0.032 & -0.001 & 0.005 \\
France & 0.068 & 0.071 & 0.024 & 0.004 & -0.015 & 0.011 \\
Germany & 0.095 & 0.069 & 0.028 & 0.006 & -0.022 & 0.011 \\
Italy & 0.054 & 0.089 & 0.034 & 0.005 & -0.003 & 0.009 \\
Netherlands & 0.081 & 0.082 & 0.033 & 0.004 & 0.009 & 0.009 \\
Norway & 0.056 & 0.068 & 0.028 & 0.009 & 0.016 & 0.014 \\
Portugal & 0.120 & 0.125 & 0.054 & 0.029 & 0.001 & 0.002 \\
Spain & 0.051 & 0.104 & 0.042 & 0.006 & 0.010 & 0.006 \\
Sweden & 0.072 & 0.058 & 0.023 & 0.005 & 0.021 & 0.015 \\
Switzerland & 0.062 & 0.047 & 0.014 & 0.002 & 0.011 & 0.012 \\
United Kingdom & 0.050 & 0.064 & 0.025 & 0.004 & 0.014 & 0.011 \\
United States & 0.071 & 0.072 & 0.026 & 0.006 & 0.012 & 0.012 \\
Average & 0.074 & 0.077 & 0.031 & 0.009 & 0.007 & 0.010 \\
Median & 0.069 & 0.070 & 0.028 & 0.006 & 0.011 & 0.011 \\
\hline
\end{tabular}

The table presents asset pricing statistics based on simulated data from our model as well as from the historical data. The historical data come from Barro and Ursua (2008). The "Constant Volatility" model is a version of the full model where we "turn off" the stochastic volatility by setting the volatility of the uncertainty shocks $\omega$ and $\omega_{\mathrm{W}}$ to zero but keep other parameters at their estimated values for the full model. For the "Mehra-Presott" model we "turn off" both the stochastic volatility and the growth-rate shocks and then we recalibrate the random-walk shocks based on the volatility of permanent consumption in the full model. These results are for a CRRA $=9$, IES = 1.5 and subjective discount factor of $\beta=0.99$. 
TABLE VII

Predictability Regressions

\begin{tabular}{|c|c|c|c|c|c|c|c|c|}
\hline & \multicolumn{2}{|c|}{ Data } & \multicolumn{4}{|c|}{ Baseline Model } & \multirow{3}{*}{$\begin{array}{c}\text { BY } \\
\text { Median } \\
\end{array}$} & \multirow{3}{*}{$\begin{array}{c}\text { BKY } \\
\text { Median }\end{array}$} \\
\hline & \multirow{2}{*}{$\begin{array}{l}\text { Median } \\
\text { Country }\end{array}$} & \multirow{2}{*}{ U.S. } & \multicolumn{2}{|c|}{ Median Country } & \multicolumn{2}{|c|}{ United States } & & \\
\hline & & & Median & 95\% Prob. Int. & Median & 95\% Prob. Int. & & \\
\hline \multicolumn{9}{|c|}{5 Year Excess Returns on Price Dividend Ratio } \\
\hline$\beta$ & -0.30 & -0.41 & -0.37 & {$[-0.97,0.18]$} & -0.38 & {$[-0.97,0.18]$} & -0.23 & -0.39 \\
\hline $\mathrm{R}^{2}$ & 0.11 & 0.24 & 0.09 & {$[0.00,0.40]$} & 0.10 & {$[0.00,0.42]$} & 0.03 & 0.05 \\
\hline \multicolumn{9}{|c|}{$\underline{5 \text { Year Realized Volatility on Price-Dividend Ratio }}$} \\
\hline$\beta$ & -0.38 & -0.81 & -0.52 & {$[-1.64,0.43]$} & -0.54 & {$[-1.68,0.40]$} & -0.10 & -0.83 \\
\hline $\mathrm{R}^{2}$ & 0.19 & 0.32 & 0.09 & {$[0.00,0.46]$} & 0.08 & {$[0.00,0.45]$} & 0.02 & 0.13 \\
\hline \multicolumn{9}{|c|}{5 Year Consumption Growth on Price-Dividend Ratio } \\
\hline$\beta$ & 0.03 & 0.02 & 0.19 & {$[0.00,0.35]$} & 0.19 & {$[0.00,0.35]$} & 0.35 & 0.12 \\
\hline $\mathrm{R}^{2}$ & 0.04 & 0.02 & 0.26 & {$[0.01,0.69]$} & 0.27 & {$[0.01,0.70]$} & 0.32 & 0.08 \\
\hline
\end{tabular}

The table reports results from regressions of excess returns, consumption growth and realized volatility at the 5 year horizon on the price-dividend ratio. Our measure of realized volatility is the absolute value of the residual from an AR(1) model for consumption growth. The first two columns report results using data from our 16 country sample and the U.S., respectively. The first column is the median across countries of the statistic in question. The next four columns report results from our baseline model for the median country and the U.S. For the baseline model, we report the median value of each statistic across 1000 simulations along with the 95\% probability interval. The last two columns report results for the models of Bansal and Yaron (2004) and Bansal, Kiku and Yaron (2012). The results for the Bansal-Yaron model are taken from Beeler and Campbell (2009). We use the end of year convention for the timing of consumption, whereby time $t$ consumption is assumed to occur at the end of year $t$.

TABLE VIII

World Long-Run Risks and Real Exchange Rate Volatility

\begin{tabular}{|c|c|c|c|}
\hline & \multicolumn{3}{|c|}{ Exchange Rate Volatility } \\
\hline & Data & $\begin{array}{l}\text { Baseline } \\
\text { Estimation }\end{array}$ & $\begin{array}{l}\text { Ignoring } \\
\text { Correlation }\end{array}$ \\
\hline Australia & 0.09 & 0.51 & 0.81 \\
\hline Belgium & 0.11 & 0.42 & 0.95 \\
\hline Canada & 0.05 & 0.51 & 0.84 \\
\hline Denmark & 0.10 & 0.47 & 0.84 \\
\hline Finland & 0.10 & 0.57 & 1.03 \\
\hline France & 0.10 & 0.40 & 0.91 \\
\hline Germany & 0.10 & 0.44 & 0.89 \\
\hline Italy & 0.10 & 0.45 & 1.00 \\
\hline Netherlands & 0.10 & 0.44 & 0.97 \\
\hline Norway & 0.08 & 0.46 & 0.87 \\
\hline Portugal & 0.10 & 0.59 & 1.09 \\
\hline Spain & 0.11 & 0.50 & 1.08 \\
\hline Sweden & 0.11 & 0.45 & 0.83 \\
\hline Switzerland & 0.11 & 0.44 & 0.79 \\
\hline United Kingdom & 0.09 & 0.44 & 0.87 \\
\hline Average & 0.10 & 0.47 & 0.92 \\
\hline Median & 0.10 & 0.45 & 0.89 \\
\hline
\end{tabular}

The table presents the standard deviation of the log change in the real exchange rate of each country with the United States. First, it presents results based on historical data from 1975-2009. Second, it presents results based on simulated data from our baseline estimates. The last column calculates counterfactual exchange rates based on the simulated data from our estimated model but ignoring the correlation between the stochastic discount factors of the two countries in question. 
TABLE A.1

Sample Period of Data

\begin{tabular}{|c|c|c|c|c|c|c|}
\hline & \multicolumn{4}{|c|}{ Barro-Ursua } & \multicolumn{2}{|c|}{ GFD } \\
\hline & $\begin{array}{c}\text { Consumer } \\
\text { Expenditures }\end{array}$ & $\begin{array}{c}\text { Total Nominal } \\
\text { Return on Stocks }\end{array}$ & $\begin{array}{c}\text { Total Nominal } \\
\text { Return on } \\
\text { Government Bills }\end{array}$ & Inflation & $\begin{array}{c}\text { Total Nominal } \\
\text { Return on Stocks }\end{array}$ & $\begin{array}{l}\text { Dividend-Price } \\
\text { Ratio on Stocks }\end{array}$ \\
\hline Belgium & 1913-2009 & $\begin{array}{c}\text { 1898-1913; 1919- } \\
\text { 1939; 1941-1943; } \\
\text { 1947-2006 }\end{array}$ & $\begin{array}{c}1890 \text { - 1944; } \\
1947-2006\end{array}$ & $\begin{array}{c}1890 \text { - 1944; } \\
1947-2006\end{array}$ & $1897-2006$ & $\begin{array}{c}1927 \text { - 1939; } \\
1951 \text {-2006 }\end{array}$ \\
\hline Denmark & 1890-2009 & 1915 - 2006 & $1890-2006$ & $1890-2006$ & $1914-2006$ & 1969 - 2006 \\
\hline Finland & 1890-2009 & $1923-2006$ & 1915 - 2006 & 1915 - 2006 & $1912-2006$ & 1962 - 2006 \\
\hline France & $1890-2009$ & $\begin{array}{l}1890 \text { - 1939; } \\
1942 \text { - } 2006\end{array}$ & $1890-2006$ & $1890-2006$ & $1890-2006$ & $\begin{array}{c}1890 \text { - 1914; } \\
1919-2006\end{array}$ \\
\hline Germany & $1890-2009$ & $1890-2006$ & $1890-2006$ & 1890 - 2006 & $1890-2006$ & $\begin{array}{l}1890 \text { - 1944; } \\
1950 \text { - } 2006\end{array}$ \\
\hline Norway & 1890-2009 & 1915 - 2006 & $1890-2006$ & $1890-2006$ & 1914 - 2006 & 1969 - 2006 \\
\hline Portugal & 1910-2009 & $\begin{array}{l}1932 \text { - 1974; } \\
1978 \text { - } 2006\end{array}$ & 1930 - 2006 & 1930 - 2006 & 1931 - 2006 & 1988 - 2006 \\
\hline Spain & 1890-2009 & $\begin{array}{l}1890 \text { - 1935; } \\
1941 \text { - } 2006\end{array}$ & $1890-2006$ & 1890 - 2006 & $1890-2006$ & $\begin{array}{l}1940 \text { - 1968; } \\
1981 \text { - } 2006\end{array}$ \\
\hline Sweden & 1890-2009 & $1902-2006$ & $1890-2006$ & 1890 - 2006 & $1901-2006$ & 1915 - 2006 \\
\hline Switzerland & 1890-2009 & $\begin{array}{l}1911 \text { - 1913; } \\
1917 \text { - } 2006\end{array}$ & 1895 - 2006 & 1890 - 2006 & 1910 - 2006 & $\begin{array}{c}1918 \text { - 1939; } \\
1966-2006\end{array}$ \\
\hline United Kingdom & 1890-2009 & $1890-2006$ & $1890-2006$ & 1890 - 2006 & $1890-2006$ & 1923 - 2006 \\
\hline United States & 1890-2009 & $1890-2006$ & $1890-2006$ & $1890-2006$ & $1890-2006$ & $1890-2006$ \\
\hline
\end{tabular}


TABLE A.2

Estimates of Country-Specific Parameters

\begin{tabular}{|c|c|c|c|c|c|c|c|c|c|c|c|c|}
\hline & \multicolumn{2}{|c|}{$\begin{array}{l}\text { Rel. St. Dev. Random } \\
\text { Walk Shock }\left(\chi_{\mathrm{i}}\right)\end{array}$} & \multicolumn{2}{|c|}{$\begin{array}{c}\text { Sensitivity to } \\
\text { Common Shocks }\left(\xi_{\mathrm{i}}\right)\end{array}$} & \multicolumn{2}{|c|}{$\begin{array}{l}\text { Average St. Dev. } \\
\text { Stoch. Vol. }\left(\sigma_{\mathrm{i}}\right)\end{array}$} & \multicolumn{4}{|c|}{$\begin{array}{lr}\text { St. Dev. Transitory Shock }\left(\sigma_{v i}\right) \\
\text { post-1945 }\end{array}$} & \multicolumn{2}{|c|}{ Average Growth $\left(\mu_{\mathrm{i}}\right)$} \\
\hline & Mean & St. Dev. & Mean & St. Dev. & Mean & St. Dev. & Mean & St. Dev. & Mean & St. Dev. & Mean & St. Dev. \\
\hline Australia & 1.80 & 0.58 & 0.40 & 0.14 & 0.0073 & 0.0034 & 0.0039 & 0.0020 & 0.036 & 0.009 & 0.013 & 0.004 \\
\hline Belgium & 0.97 & 0.44 & 0.71 & 0.13 & 0.0070 & 0.0034 & 0.0037 & 0.0015 & 0.020 & 0.008 & 0.009 & 0.005 \\
\hline Canada & 1.90 & 0.61 & 0.42 & 0.13 & 0.0082 & 0.0037 & 0.0031 & 0.0014 & 0.030 & 0.009 & 0.016 & 0.004 \\
\hline Denmark & 1.02 & 0.49 & 0.48 & 0.17 & 0.0100 & 0.0039 & 0.0065 & 0.0022 & 0.012 & 0.003 & 0.014 & 0.005 \\
\hline Finland & 3.06 & 0.82 & 0.68 & 0.16 & 0.0076 & 0.0037 & 0.0037 & 0.0021 & 0.022 & 0.008 & 0.020 & 0.006 \\
\hline France & 0.80 & 0.38 & 0.63 & 0.12 & 0.0070 & 0.0031 & 0.0018 & 0.0010 & 0.027 & 0.005 & 0.013 & 0.005 \\
\hline Germany & 0.79 & 0.41 & 0.58 & 0.15 & 0.0105 & 0.0037 & 0.0027 & 0.0013 & 0.013 & 0.004 & 0.012 & 0.005 \\
\hline Italy & 0.72 & 0.38 & 0.79 & 0.13 & 0.0093 & 0.0036 & 0.0035 & 0.0017 & 0.015 & 0.003 & 0.014 & 0.006 \\
\hline Netherlands & 0.59 & 0.33 & 0.72 & 0.15 & 0.0107 & 0.0038 & 0.0031 & 0.0016 & 0.023 & 0.005 & 0.013 & 0.006 \\
\hline Norway & 1.27 & 0.57 & 0.51 & 0.17 & 0.0092 & 0.0038 & 0.0055 & 0.0023 & 0.006 & 0.003 & 0.017 & 0.005 \\
\hline Portugal & 3.06 & 0.78 & 0.81 & 0.13 & 0.0069 & 0.0035 & 0.0046 & 0.0022 & 0.029 & 0.009 & 0.018 & 0.007 \\
\hline Spain & 0.59 & 0.37 & 0.92 & 0.07 & 0.0107 & 0.0037 & 0.0022 & 0.0013 & 0.048 & 0.008 & 0.014 & 0.007 \\
\hline Sweden & 0.77 & 0.45 & 0.47 & 0.15 & 0.0095 & 0.0038 & 0.0039 & 0.0018 & 0.025 & 0.005 & 0.016 & 0.004 \\
\hline Switzerland & 0.71 & 0.36 & 0.44 & 0.10 & 0.0058 & 0.0029 & 0.0016 & 0.0007 & 0.038 & 0.005 & 0.009 & 0.004 \\
\hline United Kingdom & 0.60 & 0.30 & 0.55 & 0.16 & 0.0105 & 0.0034 & 0.0039 & 0.0019 & 0.006 & 0.002 & 0.011 & 0.005 \\
\hline United States & 1.06 & 0.41 & 0.61 & 0.15 & 0.0081 & 0.0034 & 0.0024 & 0.0015 & 0.023 & 0.005 & 0.015 & 0.005 \\
\hline Average & 1.23 & 0.48 & 0.61 & 0.14 & 0.0086 & 0.0035 & 0.0035 & 0.0016 & 0.023 & 0.006 & 0.014 & 0.005 \\
\hline Median & 0.88 & 0.43 & 0.59 & 0.14 & 0.0087 & 0.0036 & 0.0036 & 0.0016 & 0.023 & 0.005 & 0.014 & 0.005 \\
\hline
\end{tabular}

The table presents our estimates of the posterior mean and standard deviation of the country-specific parameters in our full model. 
TABLE A.3

Asset Pricing Statistics

\begin{tabular}{lcccccccc}
\hline \hline & \multicolumn{2}{c}{ Data } & \multicolumn{2}{c}{ Baseline } & \multicolumn{2}{c}{ Simple Model } & \multicolumn{2}{c}{ Post-WWII } \\
& Median & U.S. & Median & U.S. & Median & U.S. & Median & U.S. \\
\hline $\mathrm{E}\left(\mathrm{R}_{\mathrm{m}}-\mathrm{R}_{\mathrm{f}}\right)$ & 6.87 & 7.10 & 6.99 & 7.23 & 5.41 & 5.35 & 6.46 & 6.50 \\
$\sigma\left(\mathrm{R}_{\mathrm{m}}-\mathrm{R}_{\mathrm{f}}\right)$ & 21.82 & 17.37 & 13.46 & 13.46 & 13.01 & 13.05 & 13.02 & 12.77 \\
$\mathrm{E}\left(\mathrm{R}_{\mathrm{m}}-\mathrm{R}_{\mathrm{f}}\right) / \sigma\left(\mathrm{R}_{\mathrm{m}}-\mathrm{R}_{\mathrm{f}}\right)$ & 0.32 & 0.41 & 0.53 & 0.54 & 0.41 & 0.41 & 0.51 & 0.51 \\
$\mathrm{E}\left(\mathrm{R}_{\mathrm{m}}\right)$ & 9.10 & 8.23 & 8.20 & 8.47 & 6.87 & 6.94 & 7.91 & 8.08 \\
$\sigma\left(\mathrm{R}_{\mathrm{m}}\right)$ & 21.99 & 17.89 & 13.45 & 13.46 & 13.03 & 13.04 & 13.00 & 12.74 \\
$\mathrm{E}\left(\mathrm{R}_{\mathrm{f}}\right)$ & 1.43 & 1.13 & 1.12 & 1.24 & 1.44 & 1.58 & 1.19 & 1.58 \\
$\sigma\left(\mathrm{R}_{\mathrm{f}}\right)$ & 4.57 & 3.33 & 1.53 & 1.54 & 1.27 & 1.25 & 1.42 & 1.39 \\
\hline $\mathrm{E}(\mathrm{p}-\mathrm{d})$ & 3.30 & 3.30 & 2.84 & 2.83 & 3.14 & 3.16 & 2.91 & 2.92 \\
$\sigma(\mathrm{p}-\mathrm{d})$ & 0.41 & 0.40 & 0.26 & 0.26 & 0.21 & 0.21 & 0.24 & 0.24 \\
$\mathrm{AC} 1(\mathrm{p}-\mathrm{d})$ & 0.85 & 0.90 & 0.89 & 0.89 & 0.85 & 0.85 & 0.87 & 0.87 \\
\hline
\end{tabular}

Columns labeled as "Median" report the result for the median country for each statistic. Columns labeled as "U.S." report these statistics for the United States. The first two columns are estimates from real world data from non-disaster years. We use total nominal returns and dividend-price ratios on stock from GFD and total real returns on government bills and inflation rates from Barro and Ursua (2008). The remaining columns are based on data from the three versions of our model. For returns the statistics we report are the unconditional average of the level of the ex-post real net return in percentage points (i.e., multiplied by 100). $R_{m}$ denotes the return on equity (the market), while $R_{f}$ denotes the return on a short term nominal government bond (risk-free rate). The last three rows report statistics for the logarithm of the price-dividend ratio on equity. For the model, these results are for a CRRA $=9$, IES $=1.5$, and subjective discount factor of $\beta=0.99$, and are calculated using a sample of length 1 million years. 

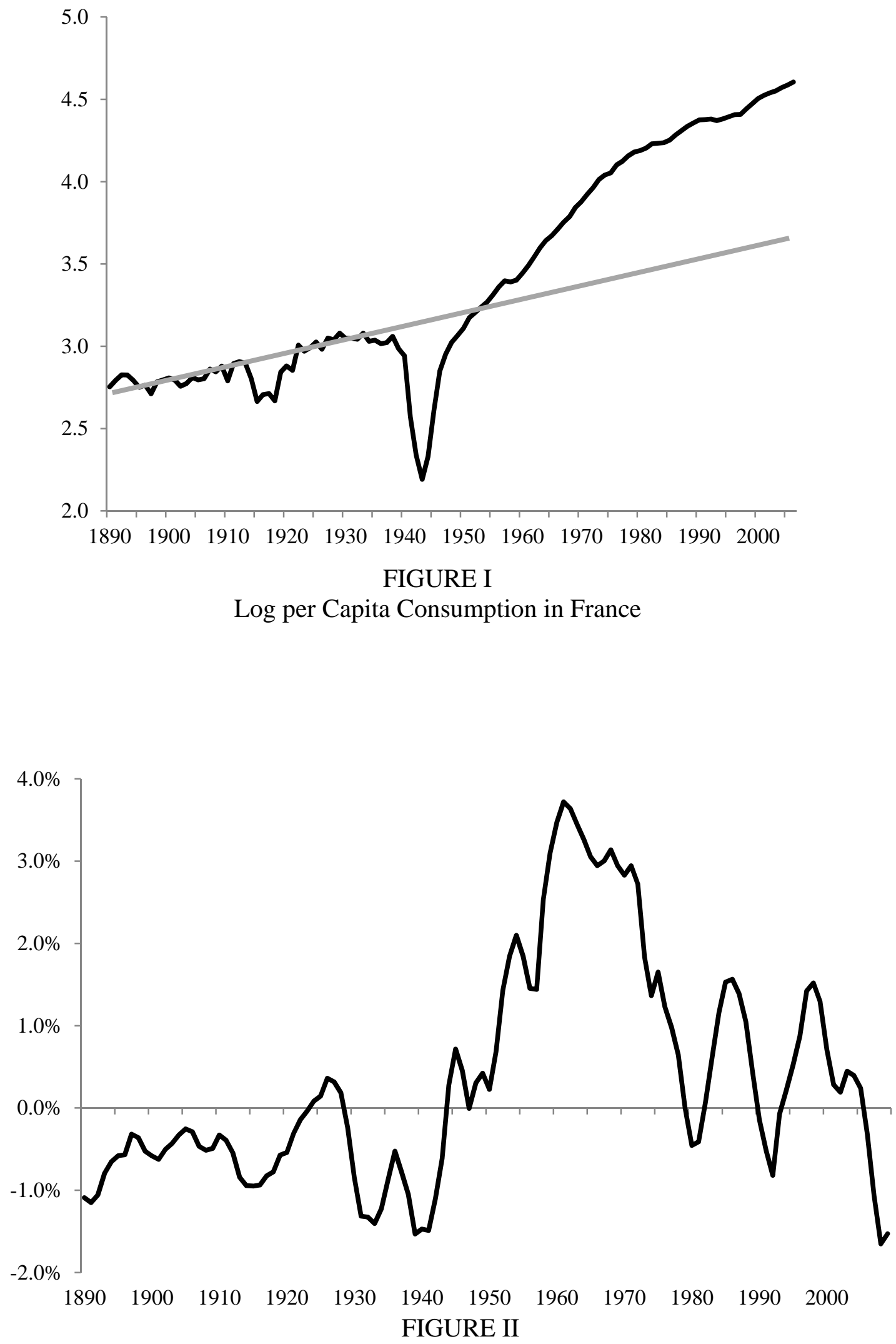

The World Growth-Rate Process

The figure plots the posterior mean value of $\mathrm{x}_{\mathrm{w}, \mathrm{t}}$ for each year in our sample. 


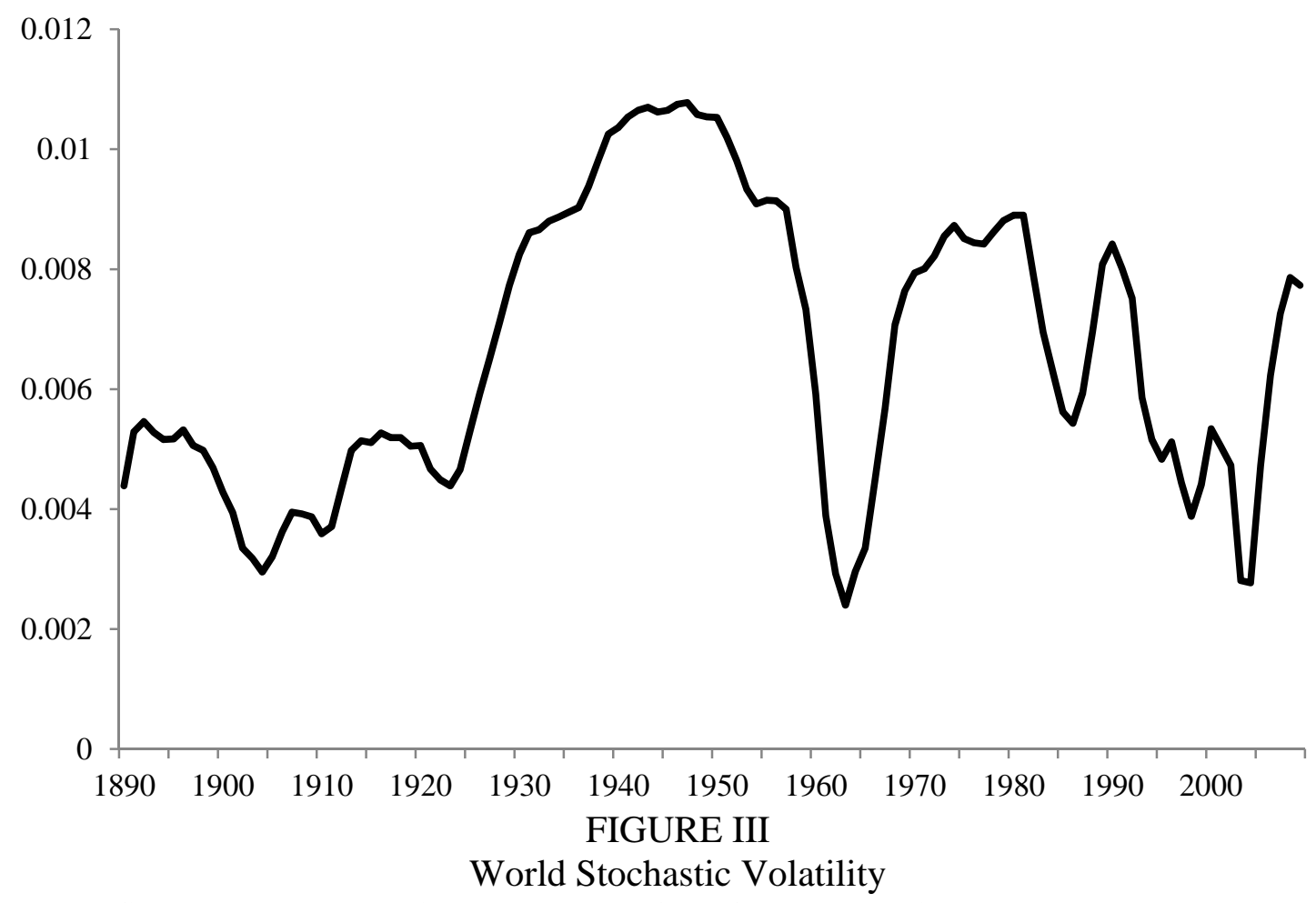

The figure plots the posterior mean value of $\sigma_{\mathrm{w}, \mathrm{t}}$ for each year in our sample.

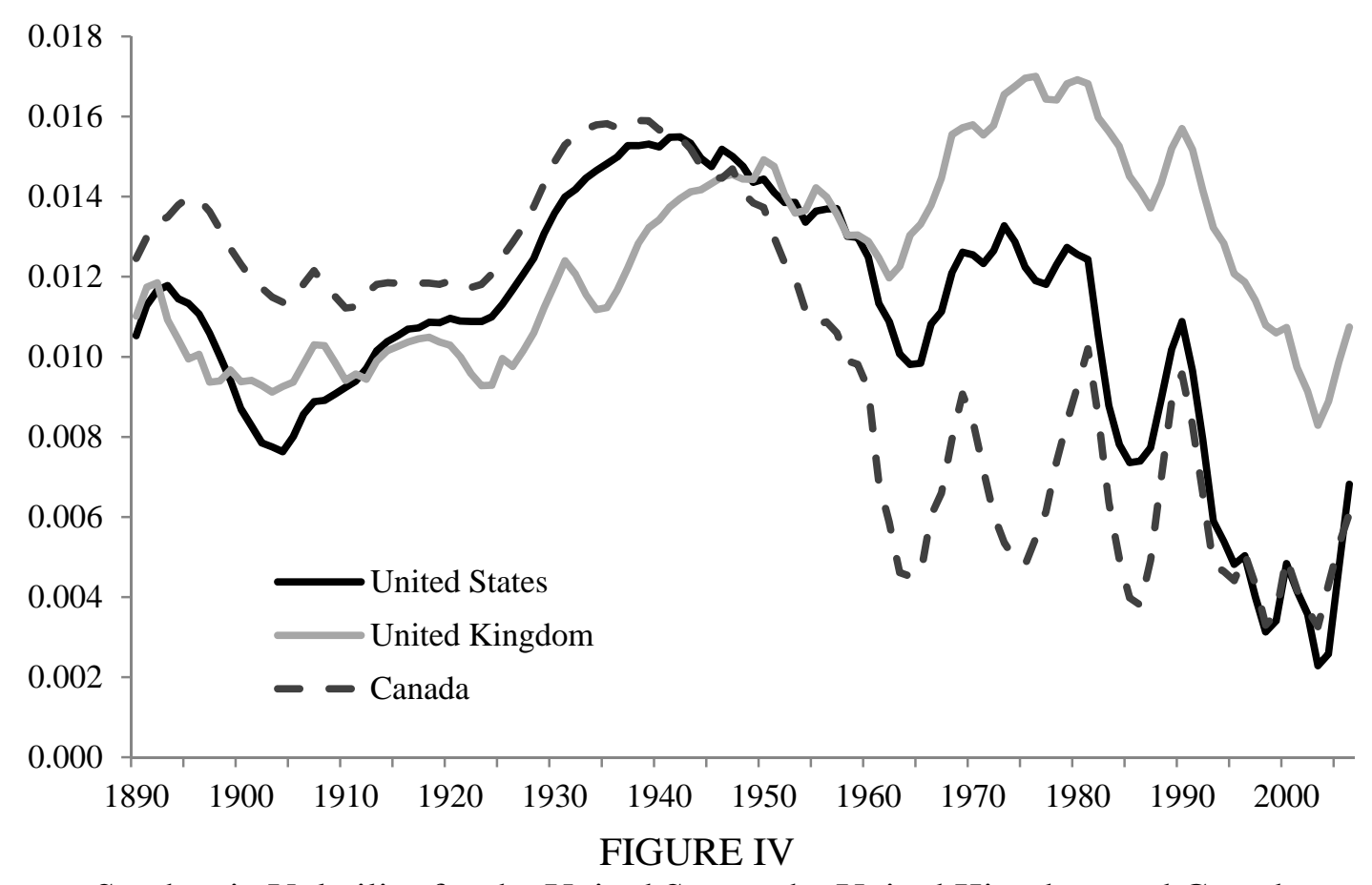

Stochastic Volatility for the United States, the United Kingdom and Canada 


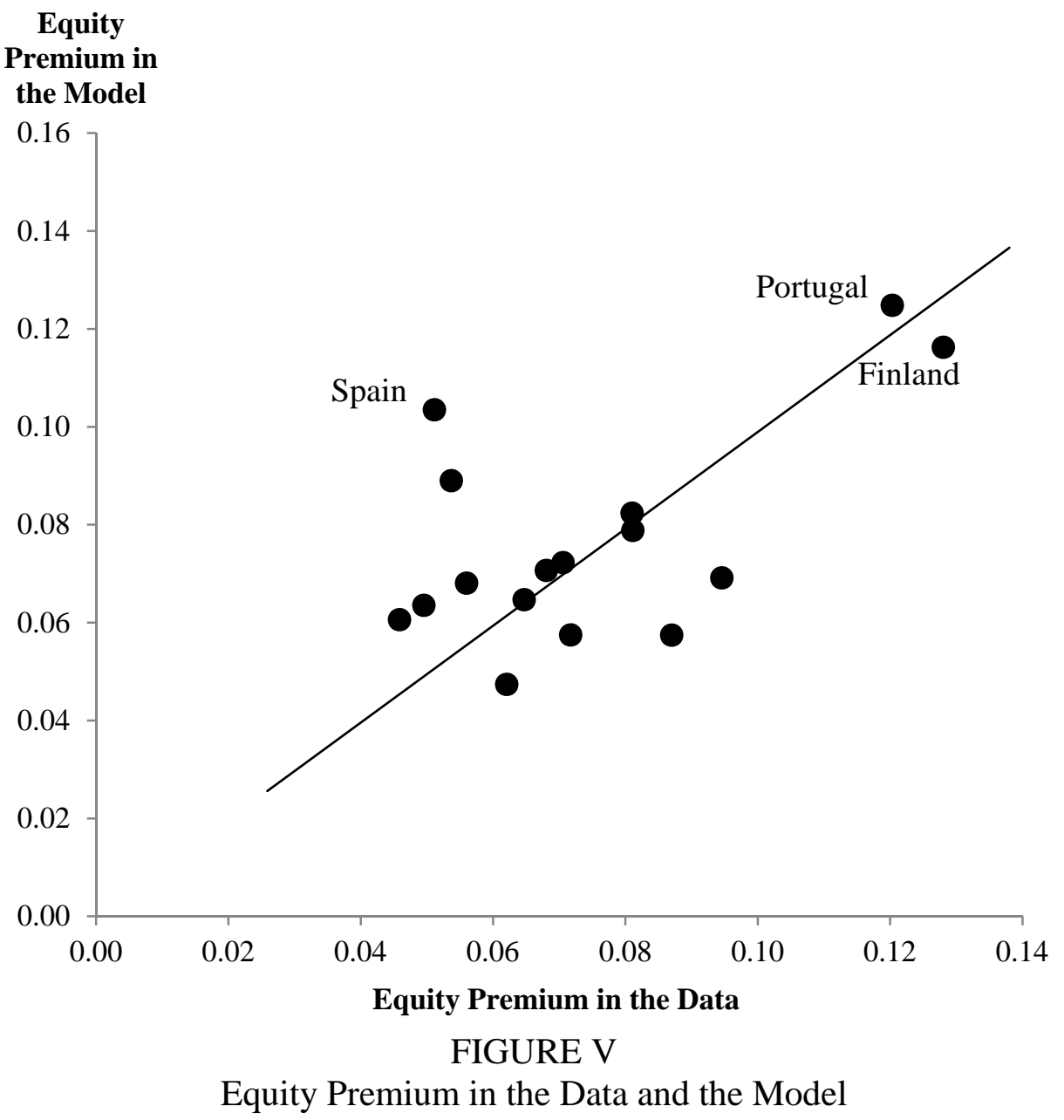

Each point gives the equity premium in the data (x-axis) and in the baseline model (y-axis) for one of the 16 countries in our sample. The figure also includes a regression line with an intercept of zero.

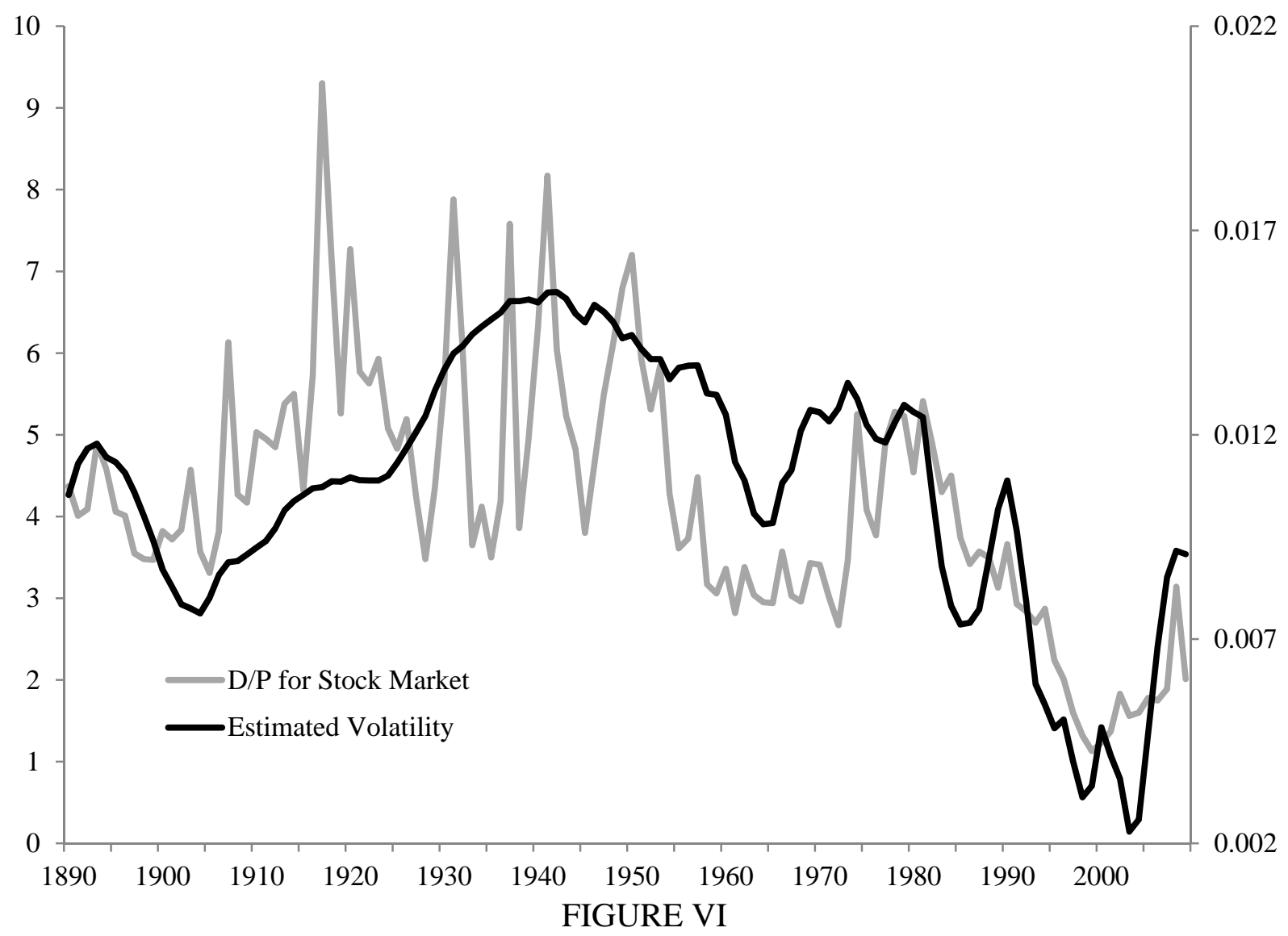

Stock Prices and Economic Uncertainty for the United States 


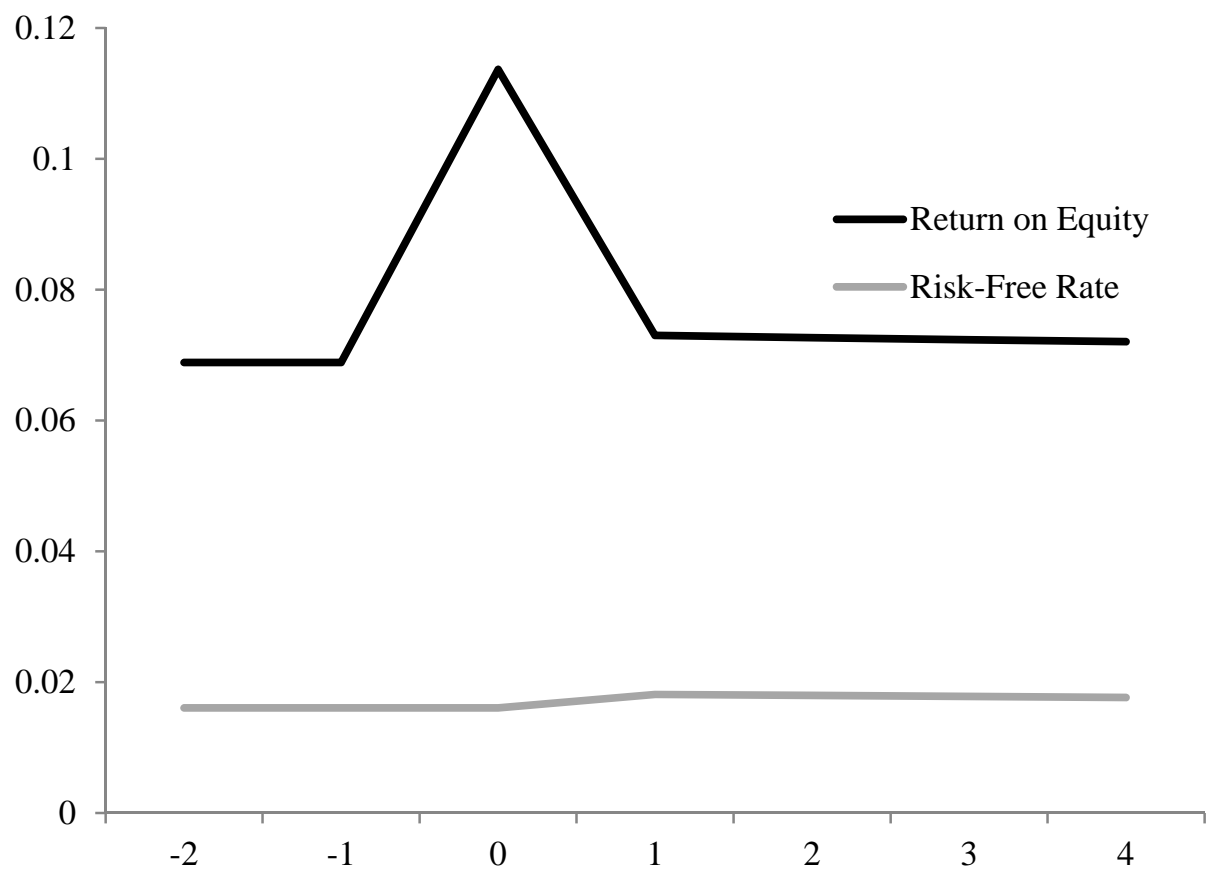

FIGURE VII

Asset Returns in Response to a World Growth-Rate Shock

Response of asset returns to a one standard deviation shock in $\varepsilon_{W t}$ starting from the model's steady state

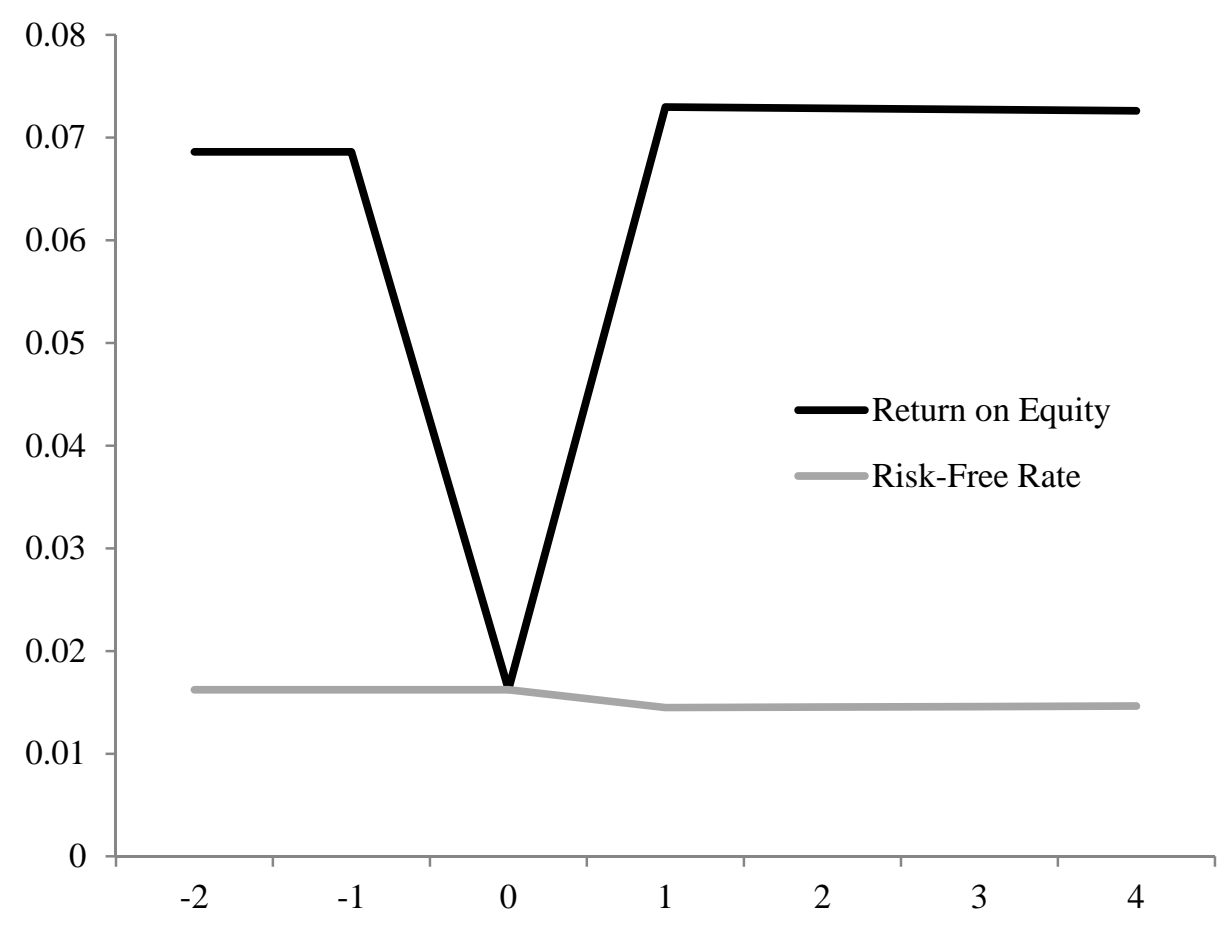

FIGURE VIII

Asset Returns in Response to a World Uncertainty Shock

Response of asset returns to a one standard deviation shock in $\omega_{W t}$ starting from the model's steady state 
Exposure Elasticity for $\varepsilon_{t}$

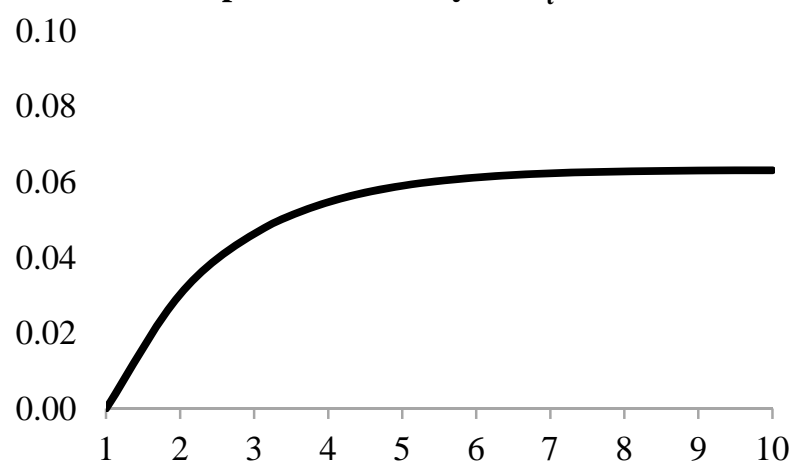

\section{Exposure Elasticity for $\varepsilon_{\mathrm{Wt}}$}

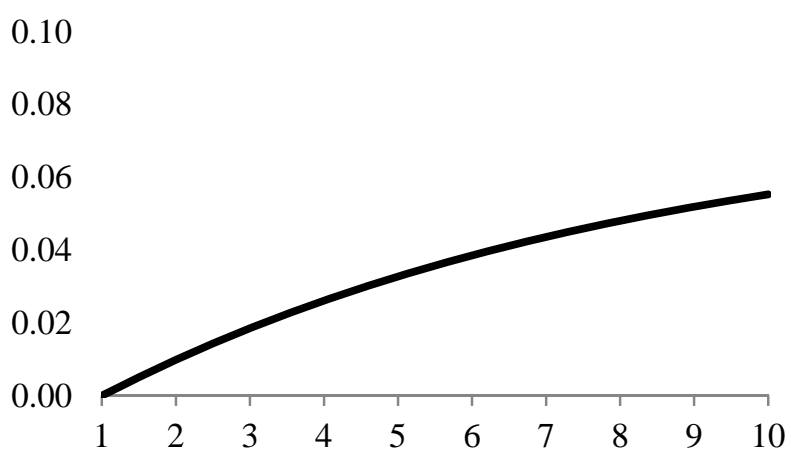

Exposure Elasticity for $\omega_{t}$

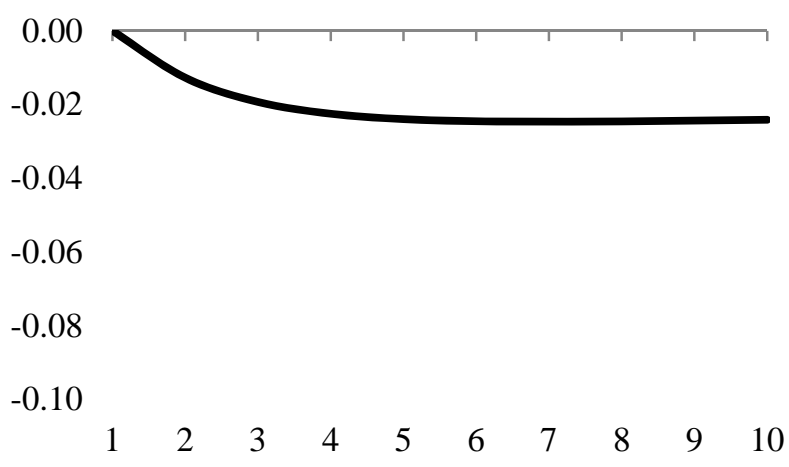

Exposure Elasticity for $\omega_{\mathrm{Wt}}$

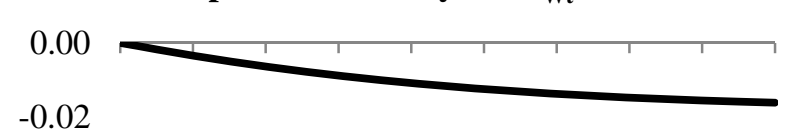

$-0.04$

$-0.06$

$-0.08$

$-0.10$
0.5

Price Elasticity for $\varepsilon_{\mathrm{t}}$

0.4

0.3

0.2

0.1

0.0

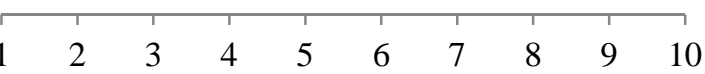

Price Elasticity for $\varepsilon_{\mathrm{Wt}}$

0.5

0.4

0.3

0.2

0.1

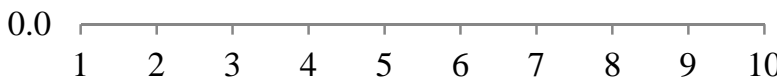

Price Elasticity for $\omega_{t}$

0.

$-0.1$

$-0.2$

$-0.3$

$-0.4$

$-0.5$

$\begin{array}{llllllllll}1 & 2 & 3 & 4 & 5 & 6 & 7 & 8 & 9 & 10\end{array}$

Price Elasticity for $\omega_{\mathrm{Wt}}$

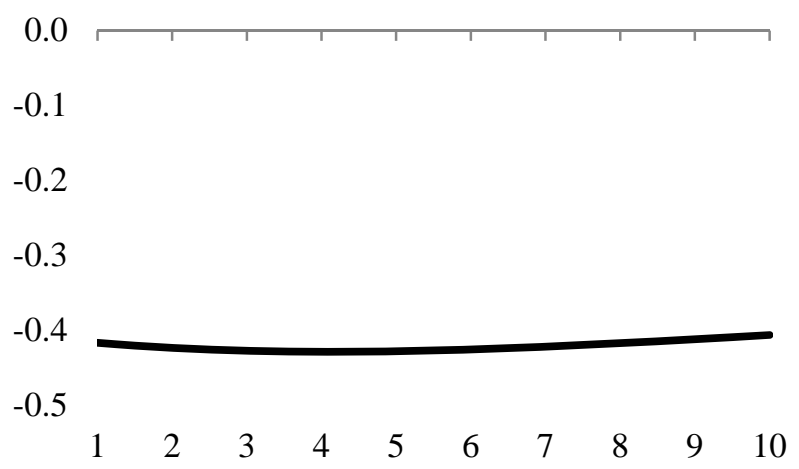

\section{$-0.1$}

$-0.2$

$-0.3$

$-0.4$

$-0.5$

FIGURE IX

Shock Exposure and Price Elasticities 